LBL-33230

UC-000

\title{
ECONOMICS, ETHICS, AND CLIMATE POLICY
}

\author{
Richard B. Howarth and Patricia A. Monahan
}

\author{
Energy and Environment Division \\ Lawrence Berkeley Laboratóry \\ Berkeley, California, U.S.A.
}

November 25, 1992

\section{MASTER}

This report was sponsored by the Stockholm Environment Institute through the U.S. Department of Energy under Contract No. DE-AC03-76SF00098. We thank Peter Gleick, Jack Huddleston, Frank Johnson, Richard Norgaard, Alan Sanstad, Lee Schipper, and Steinar Strøm for comments on an earlier draft.

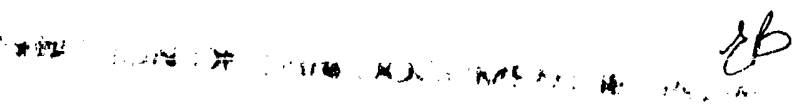




\begin{abstract}
Are the costs of greenhouse gas emissions abatement justified by the perceived benefits of sustained climate stability? Do people of the present generation have a moral right to impose climate risks on their descendants in generations to come? This report examines these questions in light of the emergent facts of climate science and their socioeconomic implications. We consider alternative normative criteria for social decision-making with particular emphasis on cost-benefit analysis and the principle of sustainable development. While each framework yields important insights, we argue that the gross uncertainties associated with climate change and the distribution of impacts between present and future generations constrain the usefulness of costbenefit criteria in evaluating climate policy. If one accepts the ethical proposition that it is morally wrong to impose catastrophic risks on unborn generations when reducing those risks would not noticeably diminish the quality of life of existing persons, a case can be made for concerted policy action to reduce greenhouse gas emissions.
\end{abstract}




\section{TABLE OF CONTENTS}

I. INTRODUCTION $\ldots \ldots \ldots \ldots \ldots \ldots \ldots \ldots \ldots \ldots \ldots$

II. ClIMATE SCIENCE - THE EMERGENT FACTS $\ldots \ldots \ldots \ldots \ldots$

A. The Greenhouse Effect $\ldots \ldots \ldots \ldots \ldots \ldots \ldots \ldots$

B. Feedback Processes $\ldots \ldots \ldots \ldots \ldots \ldots \ldots \ldots \ldots \ldots$

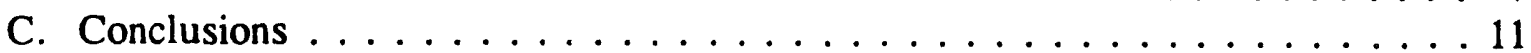

III. VALUES, WORLD VIEWS, AND THE DAMAGE FUNCTION $\ldots \ldots \ldots$

A. Quantifying Individual Impacts . . . . . . . . . . . . . . . 14

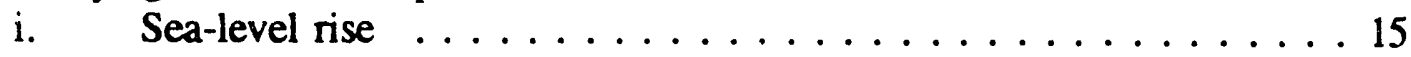

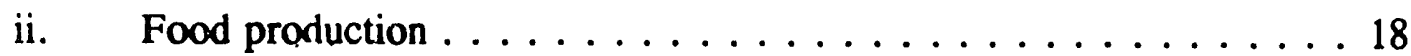

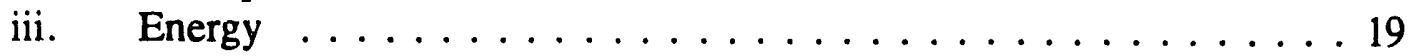

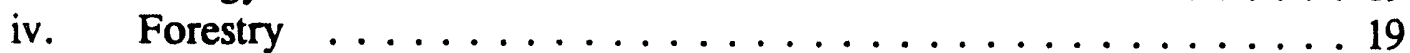

v. Non-market impacts ................... 20

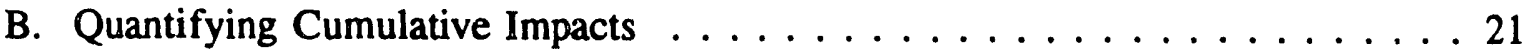

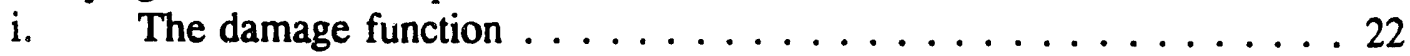

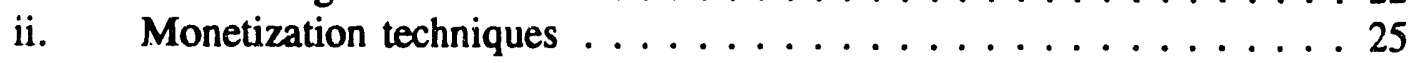

C. Conclusions ........................... 27

IV. EMISSIONS ABATEMENT: MEASURES AND COSTS . . . . . . . . . . 28

A. Non-Energy Abatement Options . . . . . . . . . . . . . . . . . 29

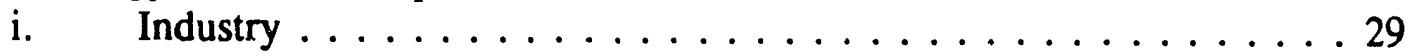

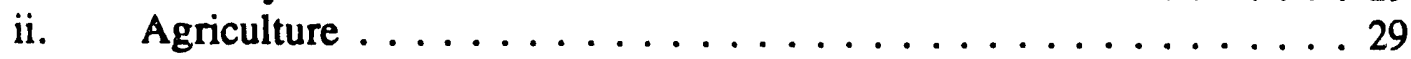

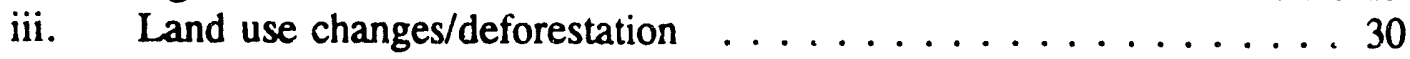

iv. Summary ....................... 30

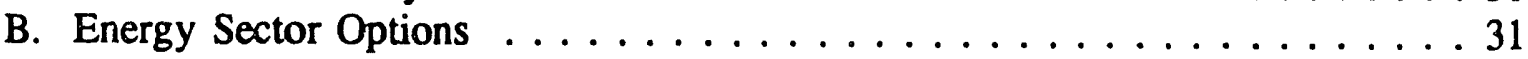

C. Implications of the Abatement Cost Calculus . . . . . . . . . . . . . . . 34

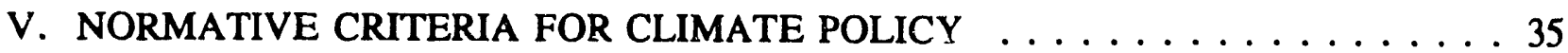

A. Cost-Benefit Analysis ....................... . . 36

i. Applications to climate policy .............. 38

ii. Cost-benefit analysis and intergenerational equity ......... 39

iii. Cost-benefit analysis and interregional equity . . . . . . . . . . 42

iv. Cost-benefit analysis and uncertainty .............. . 43

B. Social Welfare Analysis ........................ . . 44

i. The additive separable welfare function ............ 46

ii. The maximin welfare function . . . . . . . . . . . . . . 47

C. The Sustainability Criterion ..................... 49

VI. AN INTEGRATED APPROACH TO POLICY . . . . . . . . . . . . . . 54

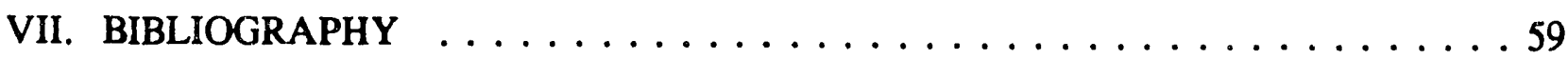




\section{INTRODUCTION}

Are the costs of greenhouse gas emissions abatement justified by the perceived benefits of sustained climate stability? Do people of the present generation have a moral right to impose the risk of a planetary catastrophe on their descendants in generations to come? While much depends on the answers to these questions, little consensus has been achieved amongst decision makers and policy analysts. In a recent article, economist Thomas Schelling (1992, pp. 7-8) answered as follows:

"[T]he developed world has no self-interest in expensively curtailing carbon consumption [while] the developing world cannot afford to incur economic penalties to slow the greenhouse effect... Insurance against catastrophes is ... an argument for doing something expensive about greenhouse emissions. But to pay a couple of percent of GNP as insurance premium, one would hope to know more about the risk to be averted."

A different perspective was put forth by climatologist Stephen Schneider (1989, p. 283):

"[T]he prospect of climatic change occurring on a global scale ten to fifty times faster than typical natural average rates of change is not one we should relish. The possibility of major environmental surprises increases with the rate at which climate changes. Moreover, if there are things we can do to slow down this rate of change that simultaneously will provide multiple benefits, then it would seem logically compelling to take them seriously... [T] he question is not whether to adopt a strategic policy of protecting the atmosphere, but rather how much to invest."

And environmental scientist Wallace Broecker (1987, p. 123) warned that:

"We play Russian roulette with climate, hoping that the future will hold no unpleasant surprises. No one knows what lies in the active chamber of the gun, but I am less optimistic about its contents than many."

The debate over global climate policy ostensibly rests on the scientific facts of the matter. If we were certain that the impacts of climate change would be gradual and easily managed by social adaptation, reducing greenhouse gas emissions would hardly appear as an urgent policy priority. If, on the other hand, we were certain that unmitigated emissions would imply calamity for the well-being of future societies, few would argue for a "go slow" approach to policy intervention.

Scientists have reached an effective consensus on a number of issues relating to climate change and the greenhouse effect. Laboratory measurements have evaluated the optical properties of carbon dioxide, chlorofluorocarbons, methane, and nitrous oxide. The atmospheric concentrations of these gases are rising rapidly due to human activities. Mathematical models based on confirmed physical laws accurately predict the mean surface temperature of the Earth and account for temperature differences between the Earth, Venus, and Mars based in part on differences in greenhouse gas concentrations in the planets' atmospheres - higher concentrations imply warmer temperatures. 
Beyond such basics, however, we are certain only of the uncertainties. Anticipated increases in greenhouse gas concentrations potentially imply moderate changes in climate. On the other hand, the possibility of extreme and unanticipated (indeed, unanticipatable) impacts on the biosphere and human systems cannot be ruled out. Some argue that we should wait for certainty before taking action. Others posit that the existing facts - including the fact of uncertainty itself - are alarming enough to tip the balance in the other direction. While the two sides use alternative interpretations of the "facts" to bolster their policy conclusions, both sides are making use of the same base of scientific information. The differences, we believe, stem as much from disparities in prior beliefs and ethical commitments as from disagreements about science per se.

This paper examines the emergent facts of climate change and their implications for social decision making. Our purpose, however, is not to review or critique the scientific literature on climate change and its potential impacts on human and natural systems. Instead, we are interested in the economic and ethical dimensions of climate change as a policy problem.

Our analysis is based on the recognition that the normative framework used to evaluate policy options has a profound influence on one's assessment of appropriate social action. If one views economic efficiency as the primary public concern, then cost-benefit analysis is the appropriate basis for "optimal" resource management. Cost-benefit analysis, however, is inherently ill-equipped to cope with the gross uncertainties associated with climate change, and alternative sets of plausible yet arbitrary assumptions yield alternative sets of "optimal" policies.

A further problem with the cost-benefit approach to climate policy is the question of equity between social groups and between present and future generations. Economic efficiency implies only that no individual or set of individuals may be made better off without rendering another worse off, yet there is no guarantee that an efficient resource allocation identified by cost-benefit analysis will ensure a favorable way of life for future generations or a fair sharing of burdens between contemporaries.

Under the rubric of "sustainable development," intergenerational equity has been widely embraced as a criterion in environmental planning. As the World Commission on Environment and Development $(1987$, p. 43) put it, "[s]ustainable development is development that meets the needs of the present without compromising the ability of future generations to meet their own needs." This definition is of course based on a value judgement, and the sustainability criterion has been attacked as inoperational by some policy analysts since its ethical spirit is not easily translated into analytical planning criteria. But consider the joint implications of the following propositions:

(1) It is morally wrong to impose catastrophic risks on members of unborn generations if reducing those risks would not significantly diminish the quality of life of existing persons;

(2) Unmitigated greenhouse gas emissions would result in a non-trivial risk of future catastrophe;

(3) Mitigation costs are today negative or zero at the margin and are unlikely to impose burdens that would noticeably impact the subjective well-being of the present generation. 
Acceptance of these postulates clearly implies an ethical obligation to take aggressive policy action. While some would disagree, we believe that all three premises are defensible on the basis of moral philosophy, environmental science, and positive economics.

One might argue for stronger or weaker premises regarding our moral commitments to ensure the welfare of future generations. Nonetheless, we believe that this framework is a powerful approach to understanding the challenge of climate policy, for it shifts the debate from an ill-defined discussion of unmeasurable costs and benefits to a discourse over positive and normative thresholds that are operationally defined given the prevailing state of human knowledge. 


\section{H. CLIMATE SCIENCE - THE EMERGENT FACTS}

While scientific consensus on the greenhouse effect - the radiative heating by greenhouse gases - is well-established, uncertainties pervade our understanding of climate feedbacks. The range of uncertainty encompasses profound social and ecological consequences. As Professor Schimel (1990, p. 68) of Colorado State University warns:

"Feedbacks between atmosphere and biosphere are non-linear, sensitive to initial conditions, and capable of enormous amplifications. Complex feedbacks in the Earth System can produce unexpected and potent responses... Without crying wolf, it is worthy of our concern as a society that biogeochemical and ecological feedbacks may result in more rapid environmental change than is predicted by purely physical models."

The scientific consensus on global warming can be summarized as follows:

(A) The greenhouse effect, the warming of the atmosphere through molecular absorption of radiation, is a well-established phenomenon. Atmospheric concentrations of greenhouse gases are increasing due to anthropogenic additions to the natural flux.

(B) Feedback processes introduce non-linearities into the system with uncertain and potentially catastrophic results; the stability of local, regional, and global systems may be affected.

If the atmospheric system were closed but for direct emissions of greenhouse gases, climate science would offer a more assured picture of global warming impacts. But the Earth system is not a test tube, climate science is inexact, and historical analogues inform us that rapid, nonlinear change may result from biogeochemical exchanges between Earth and atmosphere. We count on experts to "give us the facts," to provide a solid intellectual foundation for subsequent policy. Yet the intertemporal and uncertain nature of climate change argues for a revised expectation of what expert advice can provide. Emergent facts distilled from climate science lend insight into the complexities, uncertainties, and non-linearities of the Earth system.

\section{A. The Greenhouse Effect}

There is consensus in the scientific community regarding key aspects of both a natural and an enhanced greenhouse effect. Without the presence of greenhouse gases emitted naturally through volcanic eruption and other biogeochemical processes, the Earth's temperature would be below freezing. Trace gases in the atmosphere, including water vapor, carbon dioxide $\left(\mathrm{CO}_{2}\right)$, nitrous oxide $\left(\mathrm{N}_{2} \mathrm{O}\right)$, methane $\left(\mathrm{CH}_{4}\right)$, and chlorofluorocarbons (CFCs), absorb infrared radiation and elevate the temperature of the Earth by $33^{\circ}$ Celsius (Schneider, 1989, p. 13).

Studies of cores from ice and sediments provide a historical record of temperature trends extending tens of millions of years into the past (Lorius et al., 1988, pp. 681-4). Air temperature and $\mathrm{CO}_{2}$ concentration at the time of ice formation can be measured through an analysis of oxygen and hydrogen isotopes. The ice-core studies illuminate the intimate and predictable relationship between temperature and $\mathrm{CO}_{2}$ concentrations. In interglacial periods, the $\mathrm{CO}_{2}$ concentration is high, at about 280 parts per million by volume (ppmv), and in glacial 
times it is low, at 210 ppmv (Schneider, 1989, p. 41).

We live today at a $\mathrm{CO}_{2}$ concentration of about $355 \mathrm{ppmv}$, a level never before experienced by humans. Quantities of greenhouse gases have increased due to human activities; if population, industrial, and economic growth continue unchecked, "there will be substantial increases in the greenhouse properties of the Earth's atmosphere, which are virtually certain to create environmental change" (Schneider, 1989, p. 23). Today's increased concentration of carbon dioxide and other greenhouse gases is attributed to activities such as fossil fuel combustion, CFC use, deforestation, rice paddy agriculture, and fertilization. Energy use is the primary cause of carbon dioxide releases and is deemed responsible for nearly $57 \%$ of all greenhouse gas emissions (EPA, 1990a). Should few steps be taken to reduce greenhouse gas emissions, a doubling of carbon equivalent emissions from the pre-industrial level is anticipated in 2025 (IPCC, 1991b, p. xxxi); in a low emissions scenario, doubling occurs in 2060.

There is agreement in the scientific community that greenhouse gas emissions from human activities will impact global temperatures. The primary international group researching climate change, the Intergovernmental Panel on Climate Change comprised of over 200 scientists from around the world, concludes that:

"We are certain emissions resulting from human activities are substantially increasing the atmospheric concentrations of the greenhouse gases... These increases will enhance the greenhouse effect, resulting on average in an additional warming of the Earth's surface" (IPCC, 1991a, p. xi).

EPA (1990b, p. 27) cites other likely impacts: a globally enhanced water cycle (reflecting increases in evaporation due to warmer temperatures), melting of sea ice, polar winter surface warming (which may be as much as three times the global mean warming), summer continental dryness and warming, high latitude precipitation increase, and a rise in global mean sea level due to thermal expansion.

The controversies arise in quantifying future warming, anticipating the timing of climatic changes, and predicting social and ecosystem responses. Table 2-1 summarizes the IPCC analysis of greenhouse gas emissions and characteristics. The data on pollutant concentrations in the first three rows is subject to relatively little uncertainty, while the data on global warming impacts in the last three rows involve considerable uncertainties.

There is a substantial body of research on likely impacts should carbon dioxide equivalent concentrations double from the pre-industrial level, but very little analysis of impacts from higher concentrations or from other greenhouse gases has occurred. In his review of the IPCC reports, Schneider (1991) comments: "The most serious general problem is that the reports especially their policy aspects - focus too much on climate change up to a fixed date, 2030, instead of giving equal emphasis to the longer-term changes that will result from human actions between now and 2030."

The primary tools used to predict the magnitude of potential climate change are general circulation models (GCMs) and paleo-climatic analysis. GCMs are three-dimensional, mathematical models that synthesize current knowledge on atmospheric processes and predict 
long-term changes in surface air temperature, precipitation, and soil moisture. Paleo-climatic analysis, or the "analogue method," approximates the future through reconstructions of past climates.

Table 2-1

Groenhouse Gas Emissions and Characteristics

(adapted from IPCC, 1991a, p. 7 and p. 45)

\begin{tabular}{|r|c|c|c|c|c||}
\hline Parameter & $\mathrm{CO}_{2}$ & $\mathrm{CH}_{4}$ & $\mathrm{CFC}-11$ & CFC-12 & $\mathrm{N}_{2} \mathrm{O}$ \\
\hline $\begin{array}{r}\text { Pre-industrial } \\
\text { concentration }\end{array}$ & $280 \mathrm{ppmv}$ & $.8 \mathrm{ppmv}$ & 0 & 0 & $288 \mathrm{ppbv}$ \\
\hline $\begin{array}{r}1990 \\
\text { concentration }\end{array}$ & $353 \mathrm{ppmv}$ & $1.72 \mathrm{ppmv}$ & $280 \mathrm{pptv}$ & $484 \mathrm{pptv}$ & $310 \mathrm{ppbv}$ \\
\hline $\begin{array}{r}\text { Annual rate of } \\
\text { accumulation }\end{array}$ & $\begin{array}{c}1.8 \mathrm{ppmv} \\
(0.5 \%)\end{array}$ & $\begin{array}{c}0.015 \mathrm{ppmv} \\
(0.9 \%)\end{array}$ & $\begin{array}{c}9.5 \mathrm{pptv} \\
(4 \%)\end{array}$ & $\begin{array}{c}17 \mathrm{pptv} \\
(4 \%)\end{array}$ & $\begin{array}{c}0.8 \mathrm{ppbv} \\
(0.25 \%)\end{array}$ \\
\hline $\begin{array}{r}\text { Atmospheric } \\
\text { lifetime (yrs.) }\end{array}$ & $50-200$ & 10 & 65 & 130 & 150 \\
\hline $\begin{array}{r}\text { Global Wrmg. } \\
\text { Potential' }\end{array}$ & 1 & 63 & 4500 & 7100 & 270 \\
\hline $\begin{array}{r}\text { Radiative } \\
\text { forcing }\end{array}$ & $61 \%$ & $17 \%$ & $12 \%^{3}$ & & $4 \%$ \\
\hline
\end{tabular}

1 The Global Warming Potential (GWP) index compares emissions impacts with $\mathrm{CO}_{2}$, the standard by which other gases are evaluated. For each gas, the GWP depends on the character of molecular absorption bands, the atmospheric lifetime, the molecular weight, and the relevant time period. For this review, the GWP is on a mass basis. Thus, $1 \mathrm{~kg}$ of $\mathrm{CH}_{4}$ emissions is equivalent to $63 \mathrm{~kg}$ of $\mathrm{CO}_{2}$ in terms of atmospheric warming potential.

2 When the climate is in equilibrium, absorbed solar energy is balanced by radiation emitted from the Earth to space. Any factor that perturbs this balance is termed a radiative forcing agent. Radiative forcing refers to the anticipated share of global warming contributed by each gas. Thus, $61 \%$ of anticipated temperature change is attributed to $\mathrm{CO}_{2}$ emissions currently in the atmosphere.

${ }^{3}$ This represents the radiative forcing from all $\mathrm{CFC}$ emissions.

$$
\begin{array}{ll}
\text { ppmv } & \text { parts per million by volume } \\
\text { ppbv } & \text { parts per billion by volume } \\
\text { pptv } & \text { parts per trillion by volume }
\end{array}
$$

From a doubling of $\mathrm{CO}_{2}$, the models discussed by the IPCC anticipate equilibrium temperature changes in the range of 1.9 to $5.2^{\circ}$ Celsius, with $2.5^{\circ}$ Celsius as the best estimate (IPCC, 1991a, p. xxx). Greenhouse gases already in the atmosphere may have committed the Earth to a temperature rise of .9 to $2.6^{\circ}$ Celsius, only about $.5^{\circ}$ Celsius of which has been realized. The lag between emissions and temperature change is due to heat absorption by the 
ocean and to feedback processes.

While a $1.9^{\circ}$ Celsius temperature change may appear harmless, it would be twice the magnitude of the $1^{\circ}$ Celsius change in European temperatures that heralded the Little Ice Age between the 14th and 17th Century (Oeschger and Mintzer, 1992, p. 63). The colder temperatures induced frequent crop failure and the sporadic freezing over of the Baltic Sea, allowing people to sled from continental Europe to Scandinavia. A $5^{\circ}$ Celsius temperature increase would move the Earth to a climatic regime not experienced in over a million years.

\section{B. Feedback Processes}

What may be more interesting than what the models say, however, is what they do not. As Broecker (1987, p. 123) cautions:

"My suspicion is that we have been lulled into complacency by model simulations that suggest a gradual warming over a period of about 100 years... While I do not have any complaints about how these modeling experiments were conducted - indeed they were done by brilliant scientists using the best computers available - the basic architecture of the models denies the possibility of key interactions that occur in the real system. The reason is that we do not yet know how to incorporate such interactions into models."

Most GCMs are equilibrium, not transient models, ${ }^{1}$ and are currently not sophisticated enough to incorporate feedback processes into their analysis. Feedback mechanisms such as the temperature-sensitive liberation of greenhouse gases and changes in oceanic circulation patterns introduce non-linearities into the Earth system by dampening or enhancing temperature change. There is growing evidence from paleo-climatic data that feedbacks have resulted in abrupt, nonlinear change (Broecker, 1987; Bard et al., 1987; Heusser and Rabassa, 1989; Kennett, 1990; Hoffert, 1992). Though the exact nature of feedback processes is uncertain, the IPCC warns that "... it seems likely that, overall, [the feedbacks] will act to increase, rather than decrease, greenhouse gas concentrations in a warmer world" (IPCC, 1991a, p. xviii).

An important feedback may be the temperature-sensitive liberation of greenhouse gases like methane. The rate of methane emissions will likely increase with warmer temperatures corresponding to increases in the anaerobic decay of organic matter and through the melting of frozen sediments. Due to changes in the rate of anaerobic decay, Hameed and Cess (1983, pp. 1-7) anticipate that tropospheric methane concentrations may increase $13 \%$ to $74 \%$ with a temperature increase of 3 to $4^{\circ}$ Celsius. Even more important may be the liberation of methane currently buried in frozen sediments off the continental shelf in the Arctic Basin (Revelle, 1983, Lashof, 1989, MacDonald, 1990). Methane trapped in clathrate (crystals) beneath Arctic permafrost and along the continental shelf below the ocean floor may be outgassed as a consequence of warmer temperatures. Revelle (1983, pp. 257-259) estimates methane released

${ }^{1}$ Equilibrium models evaluate the completed change from one mean state to another. Studies of the evolution of climate over time due to altered radiative forcing, which may also be time dependent, are called transient models. There have been relatively few attempts to model the time-dependent response. 
from clathrate destabilization may cause an additional warming of $.65^{\circ}$ to $1.8^{\circ}$ Celsius.

Perhaps the largest confounding factor and potential feedback in climate change is the response of the oceans. Broecker (1987; see also Birchfield and Broecker, 1990) advances the hypothesis that the oceanic "conveyor belt," in which saline waters at the surface of the North Atlantic allow vertical circulation, ${ }^{2}$ is sensitive to changes in temperature and precipitation. Changes in oceanic circulation patterns have critical impact on climate, and according to paleoclimatic evidence, may have been responsible for rapid climatic adjustments in the past. About 10,000 years ago, a shut-down of ocean circulation may have caused a regional temperature increase as large as $7^{\circ}$ Celsius over 50 years, and a $50 \%$ increase in rainfall over 20 years (Dansgaard et al., 1989). The models cannot now, and may never be able to respond assuredly to the question of whether increasing greenhouse gas concentrations will substantively impact ocean circulation patterns and harken unanticipated and rapid changes to the climate.

Because of the complexity of modeling biogeochemical interactions, the IPCC warns that, "... we must recognize that our imperfect understanding of climate processes ... could make us vulnerable to surprise; just as the human-made ozone hole over Antarctica was entirely unpredicted" (IPCC, 1991a, p. xxcii). The ozone hole may represent an appropriate analogue for climate change; though scientists anticipated that CFC emissions were depleting the stratospheric ozone layer, the emergence of the ozone hole over the Antarctic surprised the scientific community. By using "homogenous chemistry" that ignored the unique characteristics of Antarctic clouds, ${ }^{3}$ regional impacts were not forecasted by the science.

Antithetically, surprises are thus anticipated by the science. The response of the Earth system to such disturbances is rightly a matter of scientific speculation. Feedback mechanisms bear the potential to disrupt equilibrium conditions, possibly leading to a fundamental shift in ecosystem characteristics or to radically different equilibrium conditions. Biologist C.S. Holling (1982) offers comparative models for how shocks may affect equilibrium conditions (see Figure 2-1). A system capable of absorbing shocks is visualized as a large bowl with a ball resting at its base. A jolt to the system may start the ball careening about the bowl, but the ball inevitably comes to rest, its equilibrium restored to the original state. Short-term or reversible feedbacks may provide this restorative capability. Alternatively, a shock disturbance may initiate unanticipated and potentially catastrophic consequences. Holling $(1982$, p. 11) writes:

\footnotetext{
${ }^{2}$ The specific mechanism for oceanic circulation is as follows: The North Atlantic is salty due to excess evaporation over precipitation. Salty water is more dense than fresh water, and in the winter the water sinks, inviting warm Gulf Stream water from the south. As it cools, the salty water increases in density and sinks to the bottom where it spreads out into the North Atlantic, under the Indian Ocean and into the Pacific. It then rises at the Aleutians where it again flows at the surface into the South Atlantic, across the equator and back into the North Atlantic. The thousand year cycle depends critically on oceanic salinity, evaporation, rainfall, and runoff patterns.

${ }^{3}$ Sulfuric and nitric acids that exist in the atmosphere above Antarctica in a frozen state as thin clouds are ideal surfaces for the catalytic reactions that destroy ozone (Schneider, 1989, p. 227).
} 
"[An] analogy for this [model] would be a mesa with a depression at its top. As long as the ball in the depression, the system appears qualitatively stable. If the ball is tipped over the edge of the mesa, it will move to a different position, one that could well represent extinction."

By turning the bowl over and resting the ball atop it, a system with the potential for catastrophic change is visualized. Should feedback processes prove long-term or irreversible, equilibrium conditions may be radically changed. Nature provides examples of both benign and catastrophic change due to shock disturbances, and there is thus no single model appropriate for all cases.

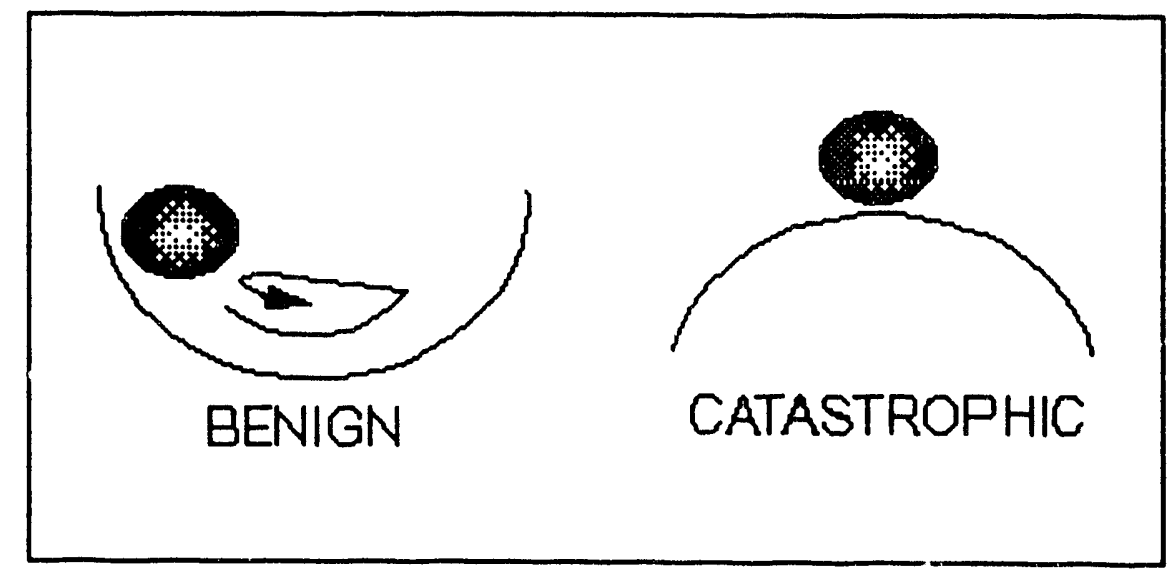

Figure 2-1

Models of System Responses to Shock Disturbances

The current set of emergent facts suggests that global warming poses a ieal societal risk in the form of a transition state. While a new equilibrium state may impact human populations in beneficial ways, there is also the risk of catastrophic ${ }^{4}$ change. Rapid climatic adjustments will change the composition of ecosystems, with some species benefiting and others unable to migrate or adapt at the rate necessary for survival. Impacts will likely be felt most acutely in regions already under stress, like those exposed to the natural hazards of coastal or river flooding, severe drought, land-slides, severe storms, or tropical cyclones (IPCC, 1991b, p. xxv). Scenarios for catastrophic regional and possibly global change include deforestation as the necessity for biotic migration exceeds capacity, an increase in the number and intensity of extreme weather events, and the melting of ice caps and subsequent inundation of coastal lands.

Changes involving biota are not well understood and offer the potential for unwelcome

${ }^{4}$ Catastrophe is defined as an event or situation which exceeds the capacity of a society to adapt or remedy, resulting in severe health, welfare, economic or ecosystem impacts. 
surprise. ${ }^{5}$ Given a warming of .1 to $1^{\circ} \mathrm{C}$ per decade, the capacity of natural communities to migrate is exceeded by factors of 100-1000 or more (Woodwell, 1990, p. 125). Ecosystems dominated by successional species (those that migrate quickly to disturbed areas) such as grasslands and savannahs may expand, while systems dominated by slower-moving species like forests will likely decrease in territory. The resulting biotic impoverishment may prove staggering and may lead to substantial release of carbon stored in biomass. Woodwell finds that a $1^{\circ}$ Celsius increase in temperature at forest-to-grassland transitions in the northern hemisphere would replace 100-200 million hectares of forests by grassland. Such a massive change in the distribution of forests would involve a release of carbon in the range of tens of billion tonnes, or over ten times the current annual amount of carbon released through deforestation.

Changes in the thermal gradient from equator to poles will shift wind and ocean currents and may affect the severity and range of storms. Mitchell and Ericksen (1992, p. 141) note that natural disasters resulted in about 2.8 million deaths over a recent 20 year period, and ihat a . change in storm intensity is worthy of social concern. MIT meteorologist Kerry Emanuel (1987, pp. 483-5) anticipates that the intensity of hurricanes could be enhanced as much as $40 \%$ with an increase in ocean temperatures of a few degrees. If large-scale weather regimes like depression tracks or anticyclones shift their position, there could be a major impact on the variability and extremes of weather (IPCC, 1991a, p. xaxiii). Hurricane Andrew offers recent and glaring example of the devastation that may result from such extreme weather events; damages from the hurricane include over 250,000 homeless; 85,000 residences destroyed; and perhaps $\$ 10$ billion in anticipated damage costs.

Currently, half of humanity occupies coastal zones. The IPCC (1991a, pp. xxix-xxx) estimates that seas will rise between 10 and $30 \mathrm{~cm}$ by the year 2030 and by 30 to $100 \mathrm{~cm}$ by the end of the next century in a "business as usual" scenario. EPA (1990b, p. 319) anticipates a one-meter rise could inundate $25-80 \%$ of U.S. coastal wetlands. However, it is the poorer nations with densely populated coastal areas that are most at risk. Some of the countries most vulnerable to sea-level rise include Bangladesh, Egypt, Pakistan, Indonesia, and Thailand, all comprised of large, poor populations. Indonesia, with $15 \%$ of the world's coastlines, is projected to lose $40 \%$ of its land surface should a one meter increase in sea level occur (Schneider, 1989, p. 149). A one-meter rise could inundate $15 \%$ of Bangladesh and all of the Republic of Maldives, Kiribati, the Marshall Islands, Tokelau, Tuvalu, and the Torres Strait Islands (Hulm, 1989, Lewis, 1989).

Mass forest die-back, more intense and frequent storms, and the inundation of coastal lands are three of many possible catastrophic scenarios. Others include shrinking or misallocated fresh water supplies (Gleick, 1992, pp. 12.7-140), mass migration of human populations, loss of biodiversity (EPA, 1991a), decreased agricultural yields (Parry and Swaminathan, 1992, pp. 113-126), and asymmetrical risks on poor populations (Lave and Vickland, 1991, pp. 283-291; Keyfitz, 1992, pp. 153-161).

\footnotetext{
${ }^{5}$ Broecker warns that "research on the continental parts of the environmental system (vegetation, soils, and waters) remains in the Dark Ages" (Broecker, 1987, p. 125).
} 


\section{Conclusions}

Because of the lag between pollutant emission and impact, climate change policy must be both anticipatory of and responsive to surprise. Actions today will likely impact generations far into the future. By the time we are assured that global warming is occurring, the warming commitment is already made, and the course of future impacts may be irreversibly determined.

Have we received a signal that global warming is occurring? The IPCC $(1990$, p. 22) anticipates "... the unequivocal detection of the enhanced greenhouse effect from observations is not likely for a decade or more." However, Houghton and Woodwell (1989, pp. 36-44) write that there are indications of an accelerated warming, citing reports of increasing depth to permafrost in the Alaskan and Canadian Arctic, an increase in the average temperature of Canadian lakes, a decline in the annual maximum extent of sea-ice surrounding Antarctica and the Arctic, and the decline of glaciers in Europe and elsewhere.

Uncertainty in itself is a key emergent fact of climate science; the science cannot procure concrete facts regarciing future impacts. The temperature rise in this century is consistent with, but not definitive in demonstrating, climate change theory. Nevertheless, there is virtual consensus that greenhouse gases will warm the atmosphere. Policies based on the emergent facts regarding climate change must account for the potential for catastrophic change from this warming. As Svedin and Aniansson (1987) warn, by "leaving out the external shocks, nonlinear responses, and discontinuous behavior so typical of social and natural systems, surprise-free analysis leaves us unprepared to interpret a host of not-improbable eventualities."

\section{Addendum to Chapter II: Updating the Emergent Facts}

As this report was being completed, the IPCC (1992) produced a comprehensive review of the most recent information on the greenhouse gas problem. The report finds that:

(1) Sulphate aerosols from sulphur dioxide emissions may have a cooling effect;

(2) The biosphere may uptake carbon dioxide at higher levels as carbon dioxide concentrations increase; and

(3) Depletion of ozone in the lower stratosphere may result in a decrease in radiative forcing, believed to be comparable in magnitude to the radiative forcing contribution of CFCs over the last decade.

Using the revised IPCC data, Wigley and Raper (1992) predict a global-mean warming of $2.5^{\circ}$ Celsius and a global-mean sea level rise of $48 \mathrm{~cm}$ over the 1990-2100 period. This translates to an average warming rate of over $.2^{\circ}$ Celsius per decade (five times the average warming over the last century) and an average rate of sea level rise of over $4 \mathrm{~cm}$ per decade (approximately four times the rate of rise during this century). While noticeably less (20-30\%) than the 1990 IPCC estimate, the projection is greater than anything experienced over the last 5000 years.

The emergent facts continue to evolve with new scientific information, but uncertainties are 
also increasing. The range of uncertainty for the Wigley and Raper study is greater than IPCC's estimates because the addition of new physical processes brings an additional set of uncertainties. Further, the new data underscore the importance of analyzing the multiple impacts, both positive and negative, of pollutants. While sulfates may reflect solar radiation and cool global temperatures, they are also held responsible for acid rain. Cooler temperatures may also result from the reduction of stratospheric ozone through reactions with anthropogenic emissions of CFCs, but increased levels of skin cancer and other health hazards may accompany the process. The revised estimates of temperature and sea level change emphasize the uncertain and rapidlyevolving nature of climate science. 


\section{iI. VALUES, WORLD VIEWS, AND THE DAMAGE FUNCTION}

As illustrated in the preceding chapter, there is a broad array of climate impacts that may befall future generations. Most of these impacts carry a socioeconomic cost or benefit that persists as long as the pollutant persists in the atmosphere. In this chapter, we discuss the process and results of valuing these impacts; Chapter $V$ will address the use of such valuations in evaluating climate policies.

Greenhouse gases are fund pollutants ${ }^{6}$ for which the environment has some assimilative capacity, but the assimilation rate is exceeded by the pace of current emissions. The damages from climate change are thus externalities in both space and time, with polluters imposing costs not only on their contemporaries around the world, but on future generations as well. ${ }^{7}$

The goal of monetizing the costs and benefits of climate change is to allow comparison of dissimilar impacts such that alternative greenhouse gas control policies can be evaluated through a consistent framework. In the ideal, valuation exercises presume analysts understand the risks of climate change; or in other words, that the complete range of possible future outcomes and their respective probabilities are known. The uncertainties inherent in the emergent facts of climate change open valuation exercises to analytical critique, since neither the range of possible futures nor their probabilities can be identified. Since surprises are by definition unanticipated, and since the emergent facts of climate change anticipate surprises, valuation exercises cannot capture all future outcomes.

Ascribing monetary values to the potential physical impacts of climate change is constrained further by issues of asymmetrical impacts, irreversibility, uniqueness of certain environmental resources, and unknown but potentially catastrophic outcomes. Given these constraints, economic analysts cannot devise secure and comprehensive damage cost estimates for climate change impacts. Instead, analysts are left to construct simplified scenarios reflecting a "best guess" approach to climate change, anticipating the timing and extent of regional impacts, and theoretically monetizing both the market and non-market impacts through consistent and replicable procedures.

As Nordhaus (1990) warns, moving from the "terra infirma" of climate change to the "terra incognita" of damage cost valuation represents a leap into the unknown. The assumptions behind the monetization profoundly impact the resulting damage cost estimates. Using the same

${ }^{6}$ Fund pollutants are absorbed or decomposed by the environment over time. Methane, for example, is removed from the atmosphere through natural processes after about 10 years, while carbon dioxide has a residence time of 100 to 200 years. Fund pollutants like greenhouse gases share some of the characteristics of stock pollutants, which are not absorbed but instead accumulate in the atmosphere. Stock pollutants, and fund pollutants with slow absorption cycles, create an interdependency between the present and future. Greenhouse gas emissions are removed so slowly from the atmosphere that future impacts depend on current actions.

${ }^{7}$ This raises questions about the appropriate discount rate to be used in converting future impacts to present value terms, a matter to be addressed in Chapter V. 
set of emergent facts regarding climate change, Nordhaus (1989, 1990, 1991a) and Cline (1992a, 1992b) derive substantially different damage cost estimates. This chapter presents (1) a description of damage cost studies for individual impacts, and (2) a discussion of how Nordhaus and Cline develop more comprehensive damage cost functions. A review of the range of damage cost studies and their selective application by Nordhaus and Cline lends insight into how the analysts' values and world views enter the valuation calculus.

\section{A. Quantifying Individual Impacts}

In theory, the total economic value of damage costs is the tripartite sum of use value, option value, and existence value (Pearce and Tumer, 1990). Use value is the benefit derived through the direct use of the environment. Option value is a more complex concept, whereby individuals derive benefit from maintenance of the option to use the environment at some future time. It is thus the potential rather than the present use value that defines the option value. Finally, existence value is the intrinsic value of nature apart from its use by humans. For example, society derives benefit from the knowledge that particular resources exist (endangered species and undisturbed landscapes, for example) and may be willing to pay a high monetary price to secure the survival or maintenance of these resources.

In practice, option and existence values are rarely accounted, and use values with ready market or non-market indicators are the primary valuation tools. It is outside the realm of analytic capability to determine the full economic values of all possible climate change impacts. For example, though climate science indicates certain ecosystems may not be able to migrate at rates necessary to assure their survival, quantifying these costs is not operational. Anticipating the economic value of a plant species with an as yet undiscovered medicinal value will baffle even the most wily analyst. Analysts have by and large ignored option and existence values in their calculations of global warming impacts, limiting their judgment of use value to those areas where market indicators are currently present. These distinctions are critical, for while such simplifications operationalize the concept of damage costing, a systematic bias results whereby impacts with ready market indicators are given economic import over impacts less handily quantified.

The intertemporal nature of climate change adds further constraint; the evolution of economic, political, demographic, and social forces and their interface with the physical environment will determine the costs of a particular impact. The relative importance of particular physical impacts cannot be judged in isolation from human activity. Current analyses assume that the breakdown of future economic activity will reflect the distribution of today. One can readily see the limitations of such an assumption when the current U.S. economic breakdown is compared with that of the year 1925. Adaptive responses will likely be enacted on a regional basis, with the structure and timing of response critical to determining the costs of climate change impacts.

Climate change will impose unequal costs (and benefits) on the world's people. Regions characterized by cold climates might benefit from moderate warming, while for semi-arid regions warmer temperatures could trigger desertification and diminished agricultural capacity. Further, an asymmetrical distribution of risk between poor countries in the South and industrialized countries in the North may result from climate change. The infrastructure in the 
South is more sensitive to climate impacts; a hurricane will more readily destroy a bamboo hut than a house made of concrete. Lave and Vickland (1991) point ou! that the South has a much larger proportion of economic activity in agriculture, a sector considered particularly sensitive to climate change, and may lack the trained agronoriists, engineers, biologists, and other experts needed for timely adaptation.

Thus far, attempts to quantify the damage costs from climate change have targeted the North and focused on impacts with market values that are considered sensitive to climate change. For example, higher temperatures will affect agricultural output, and damage costs (or benefits, should agricultural yields increase) can be estimated directly through market price indicators. Two caveats are warranted (Pearce and Turner, 1990, p. 313). First, this bias may lead to the danger of "misplaced concreteness", whereby the economic value of non-market goods is excluded from the calculus (Daly and Cobb, 1989). Second, ease of measurement is not necessarily an indication of accuracy; though the market share of agriculture in the U.S. economy is small, the loss of all agriculture would cost the country substantially more than its current contribution to national income might indicate (see Box 3-1).

The following is a description of damage cost analyses for anticipated impacts. This is not a comprehensive analysis of all damage cost studies, but represents a snapshot of some key studies. Direct economic costs relating to sea level rise, food production, energy use, and forestry, as well as indirect costs due to ozone damage, health effects, loss of biodiversity, relocation of refugees, and storm intensification, will be reviewed.

\section{i. Sea-level rise}

Today's best scientific estimate of average global sea-level rise by the year 2050 is about $65 \mathrm{~cm}$, with an uncertainty range of $31 \mathrm{~cm}$ to $110 \mathrm{~cm}$ during the next century (IPCC, 1991a, p. $x i$ ). Understanding the human ecology of coastal environments, particularly in developing countries, is fundamental to determining the impacts of sea-level rise (Warrick and Rahman, 1991). Damage costs will be determined by the diverse interactions of sea-level rise with the natural and human systems of each locale. A country with substantial agricultural production in areas affected by sea-level rise will experience different socioeconomic costs than a country with undeveloped coastal regions. Costs may include physical damage to property from waves and inundation; loss of economic production and income; land loss; costs of construction, operation, and maintenance of protective measures; cultural and social impacts; and loss of natural resources.

EPA (1989b) finds that a one-meter rise in sea-level would inundate 7000 square miles of dryland in the United States, an area about the size of Massachusetts. A large portion of this area could be protected through the construction of dikes and pumping systems at a cost of $\$ 150$ 500 per acre per year (1988\$). EPA results are summarized in Table 3-1. Given the protection of densely developed dryland, EPA estimates a sea-level rise of $50 \mathrm{~cm}$ would impose shore protection costs (expressed in total present value) of $\$ 38$ billion; $100 \mathrm{~cm}, \$ 92$ billion; and 200 $\mathrm{cm}, \$ 239$ billion. Minimizing the direct costs from sea-level rise will entail a mixed strategy of coastal defense, land-use management, and migration (Titus, 1991). Indirect costs may also result from the loss of estuarine systems, highly productive systems that cannot migrate because of restrictions in coastal geography. 


\section{Box 3-1 \\ Climate Impacts and the Role of Climate-Sensitive Industries}

Does the share of national income generated in climate-sensitive industries constitute an upper bound of the potential impacts of climate change on economic activity? Nordhaus $(1990,1991)$ amongst others implicitly argues in the affirmative: Because only $3 \%$ of Gross Domestic Product (GDP) comes from agriculture, forestry, and related sectors, climate change is ostensibly a marginal human concen.

GDP is a measure of the market value of the final goods and services sold in the economy. A sector's contribution to GDP (or value added) is equal to its total sales less expenditures on intermediate goods. By an accounting identity, value added summed across sectors adds up to GDP. But this does not mean that a sector's GDP share provides a good measure of the impacts of a shock in that sector on the esonomy as a whole.

The issue is clarified by considering a simple thought experiment. Suppose that $x$ is the total level of primary inputs availability to the economy, allocated in quantities $x_{1}$ and $x_{2}$ to a raw materials sector and a manufacturing sector that transforms raw materials into finished goods. $y_{l}=a x_{1}^{b}$ is the output of the materials soctor while $y_{2}=x_{2}^{5} y_{l}^{j+}$ is manufacturing production. If markets are competitive, then the price of each output ( $p$ ) is set equal to marginal cost, and the wage earned by the primary input ( $w$ ) is set equal to its marginal revenue product. Thus $w=p_{1} a b x_{i}^{b-1}=p_{2}(1-c)\left(y / x_{2}\right)^{c}$ and $p_{1}=p_{2} b\left(x_{2} / y_{1}\right)^{1}$.

To illustrate the point as simply as possible, it is useful to attach specific values to the parameters. Let $\mathrm{x}=100, \mathrm{a}=100, \mathrm{~b}=.5$, and $\mathrm{c}=1$. Without loss of generality, we take manufacturing output as numeraire and normalize its price $\left(p_{2}\right)$ to 1 . Under these conditions, equilibrium values for the respective variables are as follows: $x_{1}=5.26, x_{2}=94.7, y_{1}=229, y_{2}=103, w=983$, and $p_{1}=.045$. In equilibrium, the value added of the raw materials sector is $w x_{1}=p_{1} y_{t}=10,3,0$ r $10 \%$ of GDP.

Now suppose that a climate shock halves the productivity of the raw materials sector so that a is reduced from 100 to 50 . What is the net impact on the economy? As the model is structured, the allocation of primary inputs is not altered when a is changed, and the raw materials share of primary inputs and hence GDP remains fixed at $10 \%$. The productivity shock, however, lower materials production by $50 \%$ and the production of final goods and services by $7 \%$. When a is lowered to 10 , corresponding to a $90 \%$ reduction in materials output, GDP is reduced by a full $21 \%$ - more than twice the materials share of GDP in the pre-shock economy.

The point is made strikingly clear by considering the case where climate change becomes so extreme that it drives the production of raw materials to zero. Since raw materials are requisite in the production of fral goods and services, GDP would also collapse! While such an outcome is unlikely to occur in reality, this example shows that it is important to look at the feedback effects between sectors in evaluating the economic impacts of climate change. The fact that agriculture, forestry, and other climateseasitive sectors constitute a small fraction of today's economy may provide little comfort if future reductions in environmental quality substantially reduce their economic productivity. 
Table 3-1

Impact of Sea-Level Rise on the United States

(present net value in billion 1988\$)

from Titus (1991, p. 42)

\begin{tabular}{|c|c|c|c|}
\hline Sea Level Scenario & $50 \mathrm{~cm}$ & $100 \mathrm{~cm}$ & $200 \mathrm{~cm}$ \\
\hline If no shores are protected & & & \\
\hline Wetlands Lost (\%) & 17 to 43 & 26 to 66 & 29 to 76 \\
\hline Dry Land Lost (sq mi) & 3,300 to 7,300 & 5,100 to 10,300 & 8,200 to 15,400 \\
\hline Lost Property (bn 1988\$) & 78 to 188 & 165 to 451 & 411 to 1,407 \\
\hline Coastal Defense (bn 1988\$) & 0 & 0 & 0 \\
\hline $\begin{array}{c}\text { If densely developed dryland is } \\
\text { protected }\end{array}$ & & & \\
\hline Wetlands Lost (\%) & 20 to 45 & 29 to 69 & 33 to 80 \\
\hline Dry Land Lost (sq mi) & 2,200 to 6,100 & 4,100 to 9,200 & 6,400 to 13,500 \\
\hline Lost Property (bn 1988\$) & $?$ & $?$ & $?$ \\
\hline Coastal Defense (bn 1988\$) & 32 to 43 & 73 to 111 & 194 to 285 \\
\hline Open Coast (bn 1988\$) & 25 to 32 & 54 to 92 & 145 to 203 \\
\hline Sheltered Waters (bn 1988\$) & 5 to 13 & 11 to 33 & 30 to 101 \\
\hline If all dryland is protected & & & \\
\hline Wetlands Lost (\%) & 38 to 61 & 50 to 82 & 66 to 90 \\
\hline Dry Land Lost (sq mi) & 0 & 0 & 0 \\
\hline Lost Property (bn 1988\$) & 0 & 0 & 0 \\
\hline Coastal Defense (bn 1988\$) & $?$ & $?$ & $?$ \\
\hline
\end{tabular}

Gleick and Maurer (1990) conducted an exhaustive analysis of the regional costs of adapting to sea level rise in the San Francisco Bay Area. According to this study, the cost of protecting existing development from a one-meter sea-level rise will exceed $\$ 940$ million (1990\$). This figure excludes the costs of protecting or restoring wetlands or the need for more costly active structures like pumps, drainage systems, or navigation locks. With the inclusion of these costs, an additional $\$ 1$ billion may be required, and maintaining these defenses may approach $\$ 1$ million annually.

It should be kept in mind that costs to the U.S. are not necessarily reflective of costs in the South, where poverty will likely restrict choice in responding to sea-level rise and asymmetrical risks may result. In countries like Pakistan, Bangladesh, Egypt, Indonesia and Thailand, sealevel rise is projected to consume more land than in the U.S., high front-end costs and lack of 
capital may preclude the construction of coastal defense structures, and vulnerability in terms of food production and displacement (resulting in an increase in the number of environmental refugees) may lead to costly system shocks far exceeding direct costs. The asymmetrical risks faced by poor countries is underscored by IPCC (1991b, p. 153) estimates of annual protection costs as a percentage of GNP for a one meter sea-level rise. Over the next 100 years, North America is expected to spend $.03 \%$ of GNP for sea-level protection, Central America would spend .12\%, the small islands of the Pacific Ocean would spend .75\%, and the small islands in the Indian Ocean would spend nearly $1 \%$ of GNP. Certain atoll islands may be required to spend as much as 10-20\% of GNP for coastal protection (IPCC, 1991b, p. 152).

\section{ii. Food production}

Food supply is perhaps the area where climate change may carry the most acute impacts, though current scieatific knowledge is insufficient to allow regional prediction with much confidence. While elevated carbon dioxide levels and longer growing seasons tend to enhance plant yields under laboratory conditions, shifts in soil moisture (Parry, 1990), increased range of pests and diseases (EPA, 1990b), and changes in the probability of extreme weather events (Mearns et al, 1984) might lead to reduced yields. The models used to extrapolate the costs on agriculture from climate change are unable to predict the linkages between the ecological effects of photosynthetic efficiency and temperature, sunlight and moisture availability.

Impacts to agriculture in the North, where adaptative technologies are superior to those in the South, have received the most analytical attention. For the U.S., the National Academy of Sciences postulates that the fertilization effect of carbon in the atmosphere may balance losses due to heat stress, and concludes: "... we do not regard the hypothesized CO2-induced climate change as a major direct threat to American agriculture over the next few decades" (National Research Council, 1983, p. 45). A more thorough study by EPA (1990b, p. 390) finds that food production in the U.S. might either increase or decrease by as much as $\$ 10$ billion annually for a doubling of carbon dioxide in the atmosphere. This net effect of zero is attributed in part to the balancing of the gains due to the carbon fertilization effect with the losses associated with higher temperatures. The presense of gases other than carbon dioxide, however, will dampen the carbon fertilization effect; EPA's estimated gains are overstated for a doubling of carbon dioxide equivalent, and costs may thus be expected to exceed the estimate.

On a global level, Parry and Swaminathan (1991) contend that agricultural yields can be sustained only at a high, unidentified cost. Parry (1990) estimates that a global warming of $1.1^{\circ}$ Celsius by the year 2030 would lead to a decrease in U.S. agricultural output of $\$ 33$ billion annually, with reductions of $20 \%$ in sorghum, $13 \%$ in corn, and $11 \%$ in rice. He identifies greater risk in arid areas like the Sahel, and argues that higher agricultural output in areas that benefit would not compensate for agricultural losses, even taking account of $\mathrm{CO}_{2}$ fertilization.

Kane, Reilly and Tobey (in Nordhaus, 1991, p. 43) estimate the general-equilibrium impacts of climate change in a world agricultural model. In their optimistic scenario, real world income increases by more than .1\% over a half century or more; in their pessimistic scenario, world output decreases $.3 \%$.

In analyses conducted for the IPCC, Parry (1990) and Parry and Duinker (1990) test the 
sensitivity of the world food system to changes in climate. Their preliminary results indicate that there would not be a major interruption of global food supplies for yield reductions of up to $20 \%$ in the major mid-latitude grain exporting regions. However, they also find that the increase in food prices (perhaps as much as $7 \%$ under a $10 \%$ yield reduction) could seriously hamper the ability of food-deficit countries to pay for food imports.

In "low-income economies" as classified by the World Bank, 31\% of GDP was produced in the agricultural sector in 1987 (Nordhaus, 1991a, p. 45). These countries will likely be more vulnerable to changes in agricultural production. Parry and Swaminathan (1992) find that the areas most likely to see yield decreases include North and West Africa, parts of Eastern Europe, North and Central China, and Eastern Brazil. Traditional agricultural systems may be more sensitive to climate change, lacking the capital and the expertise for rapid adaptation (Lave and Vickland, 1991). Given that the human population of the planet is expected to double by the year 2100 (Keyfitz, 1992), that most of this growth will occur in the developingssorld; and that nearly $16 \%$ of today's population is underfed, the range of costs and benefits to the South from fluctuations in agricultural output will likely exceed costs and benefits in the North.

As Parry and Swaminathan (1992, p. 120) warn, predictions on the impact of climate change on global food supplies are "based more on intuition than on knowledge derived from specific study." While climate change may enhance yields and lead to global benefits, the risks attached to a reduction in yield are great. The analysts estimating the damage cost estimates for agriculture acknowledge that the complex linkages of agricultural output with a warmer atmosphere elude absolute quantification, and that current cost estimates reflect substantial analytical judgment.

\section{iii. Energy}

Warmer temperatures will affect household energy use for both cooling and heating. EPA (1990b, p. 586) has estimated additional costs to the U.S. for capital and operating expenses to provide increased electricity requirements for space cooling and benefits from reduced electric heating. Assuming an average temperature increase of $1.2^{\circ}$ Celsius by the year 2010 and $3.7^{\circ}$ Celsius by the year 2055 , additional annual electricity costs are expected to amount to $\$ 4.5$ billion (1986\$) by 2010 , rising to between $\$ 33$ and $\$ 73$ billion annually by 2055 . EPA makes no estimate for the reduction in non-electric heating costs that may result from warmer temperatures.

\section{iv. Forestry}

There has been no major study evaluating the specific costs imposed by climate change on forest resources. There is inconclusive evidence on whether the forest products industry will benefit from $\mathrm{CO}_{2}$ fertilization or shrink (Woodwell, 1990) in a warmer world. EPA (1989a, pp. 83-84) cites studies that indicate the U.S. could lose $23 \%$ to $54 \%$ of standing biomass in the Great Lakes region and $40 \%$ in western forests. The costs (or benefits) to society would depend in large part on (1) whether forests could migrate at sufficient rate to maintain current productivity rates, (2) the impact on recreation and park management from migrating forests, (3) the balance between the benefits from $\mathrm{CO}_{2}$ fertilization and the costs of increased air pollution and environmental stress on productivity of marketable forest resources, (4) the impact 
that forest migration would have on the fuel supply of developing nations, and (5) changes in water balances as the migration of forests alters runoff patterns. Damage costs will likely be non-negative, but quantification may present insurmountable difficulties.

\section{v. Non-market impacts}

Even more difficult to quantify are the non-market costs of climate change due to health effects, relocation of refugees, loss of biodiversity, storm intensification, and increased political tensions. Attempts to quantify such impacts have been few and fraught with caveats, though they indicate that costs are non-negative and may be substantial.

Haines (1990, p. 149) postulates that "[t]he primary effects of temperature on human disease are likely to be outweighed by secondary effects on health of climate change. In particular, the adverse effects on food production, availability of water, coastal flooding, and on disease vectors should be a cause of concern..." Damage costs for human health include costs for medical attention, lost income, and the most intractable of damage cost calculations, the loss of human lives. Particularly in the developing world where the accessibility of medical services is limited, the costs associated with an increase in vector-borne diseases like yellow fever, malaria, dengue, and leishmaniasis (IPCC, 1992) could prove substantial. In both the developing and industrialized nations, health costs associated with respiratory problems and heat stress incidents are likely to rise as the amount of ozone and other photo-chemical oxidants increases. If no acclimatization occurred, summer mortality in the U.S. with a doubling of carbon equivalent is estimated to rise from a current total of 1,150 deaths to about 7,400 deaths (Kalkstein et al., in Haines, 1990, pp. 151-2). Warmer temperatures cause pollution levels and associated health costs to rise; EPA (1990b) anticipates that a $4^{\circ} \mathrm{C}$ increase in temperature in San Francisco would increase ozone concentrations by $20 \%$, and Freeman (1979) estimates this percentage reduction in current air pollution levels would save $\$ 17$ billion (1978\$) in health costs due in particular to reduced respiratory illnesses. Other potential and non-quantified health costs may be attributed to changes in agricultural output, water supply, storm intensity, and sea-level rise.

Substantial numbers of people may need to be relocated due to sea-level rise, changes in agricultural structure, forest migration patterns, changes in water availability and other climate change impacts. Relocation costs include lost income (in terms of both property and wages), travel and lodging expenses, and social costs associated with the overcrowding of cities. Assuming a sea-level rise of .79 meters by the year 2050 and 2.17 meters by 2100 , Jacobson (1989) anticipates the homes and livelihoods of 46 million self-supporting people will be lost. Ayres and Walter (1991) estimate that as many as 100 million people in the world may be displaced with a doubling of carbon equivalent, and that resettlement costs may total $\$ 1$ trillion (1991\$).

Damage costs relating to the loss of biodiversity consist of a complex calculation in which option and existence values play dominant roles. Option values are necessarily anticipatory and incalculable; economic impacts must be perceived before they can be valued. The loss of a plant species with medicinal value yet undiscovered or with market potential as an input into production processes (i.e., biotechnology) is a social cost for which no valuation can be made. Direct economic costs, which are more easily calculated, include the extinction of a food source or loss of forests for timber production. Indirect costs include: degradation of atmospheric and 
aquatic quality; increased flooding; loss of a genetic library; and degradation of food webs and nutrient cycling. Though empirically elusive, maintenance of biodiversity may represent significant value to the current and future world society.

The intensification of extreme weather events may precipitate greater frequencies of droughts, flooding, storms, and fires, though the emergent facts cannot provide either confirmation or negation. If historical weather-related impacts are reflective of climate change impacts in the future, absolute economic losses will be heavier in rich countries, but poor countries will be disproportionately affected. Relative to GDP, the impact of weather-related disasters can be 20 to 30 times larger in the South than the North (Mitchell and Ericksen, 1992, p. 146). It is not unusual for a severe typhoon to wipe out all agricultural output for a South Pacific island for a single year. Estimates of global economic losses from current natural disasters range from $\$ 25$ to $\$ 100$ billion per year (Kates, 1979), though no estimate of how climate change may modify such valuations has been made. More costly may be the loss of human lives, particularly in the South; during a recent 20-year period, natural disasters resulted in 2.8 million deaths (Mitchell and Ericksen, 1992, p. 141), and even a 1\% increase in deaths attributable to natural disasters would translate into 1,400 additional deaths per year.

Other non-market costs, like the costs of increasing political tensions due to water reallocation (Gleick, 1992) or to North/South tensions over culpability and asymmetrical risks may further increase the costs associated with climate change. Unless the links between climate, consequence, and the market are easily discernable, costs such as these will remain outside the damage cost calculus. Monetization cannot "levelize the playing field" to assure all costs and benefits are included in the valuation calculus, and economic commensurability is thus an unrealizable goal. Preliminary evidence suggests the costs and benefits associated with nonmarket impacts may be substantial, but uncertainties will continue to hamper the development of consequential estimates.

\section{B. Quantifying Cumulative Impacts}

Based on problem perception, analysts create scenarios that simplify potential impacts from climate change and allow for wieldy analysis. The substantial and potentially irreducible uncertainties of climate change forecasts lead analysts to embrace "best guess" approaches to scenario development, with hardy reliance on belief systems, experience, and personal hunches to interpret and monetize the emergent scientific facts. An optimistic scenario may be just as plausible as a pessimistic scenario, but the resultant damage cost estimates will differ greatly.

Nordhaus selects an optimistic scenario on which to build his analysis, where climatic changes occur gradually enough for social adjustment. Nordhaus (1991a, p. 46) states that "climate change will lead to a combination of gains and losses with no strong presumption that modest and gradual global greenhouse warming will on balance be harmful." This optimistic scenario is shaped by two key assumptions. First, people and their economic activities can exist, and indeed can thrive, in a wide range of climatic zones. Secondly, changes in temperature that occur naturally through the day will play more prominent a role in our lives than will potential changes due to climate change. Nordhaus (1991a, p. 40) writes:

"The variations in weather that we experience in our daily lives will swamp the likely 
changes over the next century. The change in temperature while this paper is being read is likely to be greater than the expected change from 1990 to 2090 . Few people are likely to notice the $\mathrm{CO}_{2}$ signal amidst the noisy pandemonium of their daily lives."

Cline (1992b) chooses a less optimistic scenario, assuming that climatic changes will lead to more significant social disruption. Cline (1992b, p. 376) presumes "[the] greenhouse effect poses major risks, especially over the very long term of two to three centuries, by which time temperatures could rise by as much as $10^{\circ}$ to $18^{\circ} \mathrm{C}$." Cline finds the range of human activities subject to climatic disruption to extend beyond the realm examined by Nordhaus, and includes in his calculations less easily quantified impacts like species loss, migration, and infrastructure degradation.

\section{i. $\quad$ The damage function}

The shape of the damage curve bears profound consequences for climate policy evaluation. A linear damage function assumes catastrophes to be non-realizable, change to be gradually occurring over time, and non-linear impacts to be outside the realm of possibility. A geometric damage function assumes that an additional greenhouse gas molecule will cause more damage than the preceding molecule and that the timing of emissions will affect the degree of damage attributable to them. Both functions ignore the potential for rapid change at a particular pollutant threshold level.

According to the Nordhaus scenario, climate change is of minor consequence relative to diurnal temperature fluctuations and to more pressing social issues. The selected marginal damage function is thus linear, reflecting a modest degree of damages and no significant risk of non-linear or catastrophic consequence. With a linear damage function, a two tonne carbon release will induce twice the damage costs of a one tonne release.

Cline, on the other hand, portrays the damage function as geometrically increasing. Like Nordhaus, Cline assumes the future breakdown of economic activity to reflect current conditions. Damages per unit of economic activity (d) are specified by the function

$$
\mathrm{d}=\mathrm{d}_{1} \times\left[\Delta \mathrm{T} / \Delta \mathrm{T}_{1}\right]^{1.3} \text {. }
$$

where $\Delta T$ is the increase in temperature relative to the pre-industrial norm while $d_{1}$ and $\Delta T_{1}$ are the damage level and temperature change associated with a doubling of carbon equivalent. The temperature increase $(\Delta T)$ is dependent on the quantity of past emissions remaining in the atmosphere at a particular moment in time $Q(t)$, where

$$
\Delta T=\Delta T[Q(t)]
$$

The science is consistent with each of these possible damage functions, though the historical record provides evidence that changes can occur abruptly, catalyzing ecosystem changes at a rate exceeding the capacity of natural systems to evolve, migrate, or adjust. Though both Cline and Nordhaus postulate that the possibility of catastrophic consequences could affect the damage functions, their scenarios do not include direct estimates of such damage costs. Cline (1992a, pp. 46-47) in particular discusses the possibility of catastrophic change, warning that: "There 
is ample room for unpleasant surprise from global warming... It is even more difficult to place a quantitative evaluation on these catastrophe scenarios than on species loss. However, their economic damages would be immense, and their probability is certainly above zero." Figure 3-1 illustrates three types of damage functions: linear, geometric, and catastrophic (with discontinuous, threshold impacts). All three damage functions lie within the realm of possibility in the uncertain prospective of climate change.

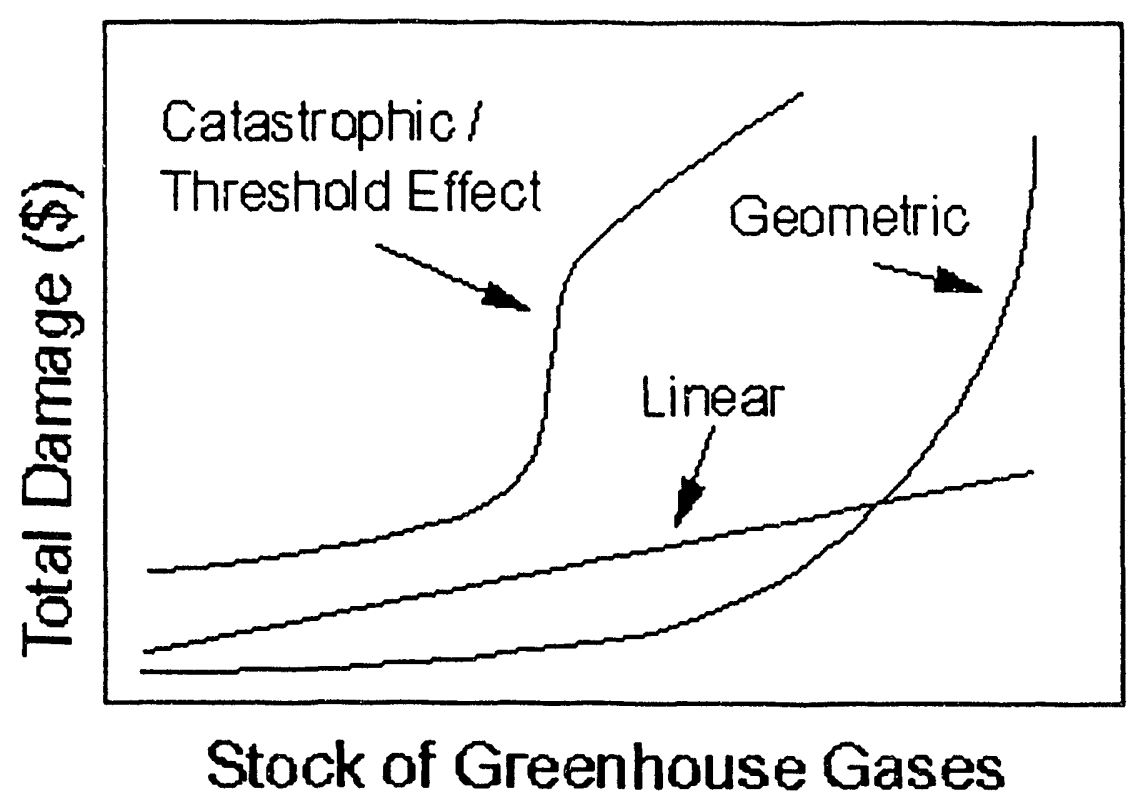

Figure 3-1

Possible Global Warming Damage Functions 
Table 3-2

Damag $_{\text {, Costs to the U.S. }}$

for a Doubling of Carion Equivalent Greenhouse Gases* (in billion $1981 \$$ per year)

\begin{tabular}{|l|r|r|}
\hline \multicolumn{1}{|c|}{ Study } & Cline**, & Nordhaus, \\
\hline 1981 national income & 2415.1 & 1991 \\
\hline Forestry & 1.6 & 2415.1 \\
\hline Electricity/Energy & & \\
\hline Air cond. & 5.5 & \\
\hline Heating & -.6 & 1.65 \\
\hline Sea Level Rise & & -1.16 \\
\hline Loss of land & 2.9 & \\
\hline Coastal protection & .6 & 1.5 \\
\hline Recreation & .8 & 3.7 \\
\hline Ozone impacts & 1.7 & not quantified \\
\hline Health & 2.9 & not quantified \\
\hline Water & 3.5 & not quantified \\
\hline Agriculture & 8.6 & -9.7 to 10.6 \\
\hline Species Loss & 2.0 & 6.2 \\
\hline Migration & .2 & $.26 \%$ \\
\hline Hurricanes & .4 & not quantified \\
\hline Urban infrastructure & .05 & not quantified \\
\hline Total & 30.1 & 6.2 \\
\hline \% of 1981 income & $1.25 \%$ & $.26 \%$ \\
\hline & & \\
\hline & & \\
\hline & & \\
\hline & & \\
\hline
\end{tabular}

- Both analysts assume the breakdown of economic activity in the future to reflect the current status; thus, there is no dynamic analysis of sectoral change or economic growth potential.

* Cline uses the 1990 breakdown of economic activity in his calculations. According to the International Financial Statistics (1991), the national income for 1990 was $\$ 4889.5$ billion. To convert Cline's damage costs from the 1990 into the 1981 economy, we performed the following calculations:

(1990 damage cost)/(1990 national income) $x$ (1981 national income) 


\section{ii. Monetization techniques}

To monetize the impacts of climate change, a number of simplifying assumptions must be made about the future of the global and national economies, market sectors vulnerable to climate change, and the sensitivity of non-marketed goods and services to climate change. As the earlier section illustrates, economic commensurability reflects the nexus of "best guess" climate change impacts with the market. Antithetically, even at this nexus there is a range of economic opinion as to the proper valuation. As illustrated in Table 3-2, Nordhaus and Cline select from alternative damage cost studies to arrive at very different direct cost estimates for a doubling of carbon equivalent.

Nordhaus focuses on the damage costs to those areas of the economy for which market indicators are available. Using the 1981 breakdown of the U.S. economy, Nordhaus estimates that $3 \%$ of the economy is sensitive to climate change, while an additional $10 \%$ is modestly sensitive. ${ }^{8}$ Cline extends possible damage costs beyond Nordhaus' $13 \%$ limit, evaluating impacts like storm intensification with no ready market indicators. Both analysts assume the breakdown of the economy in the future will reflect the current structure.

To approximate the damage costs of sea-level rise, both Nordhaus and Cline rely upon EPA estimates. Their estimates for the total costs from sea-level rise are thus similar, though they relied upon different EPA scenarios regarding the mix of land loss and coastal protection costs. For the remaining damage cost calculations, however, they rely on alternative studies to substantiate divergent results.

Agriculture and energy costs reflect the greatest divergences between the Nordhaus and Cline estimations, and discussion on how they were calculated sheds light on how values and world views shape monetization analysis. Nordhaus and Cline base their estimates of agricultural cost impicts on a combination of scientific studies and professional judgement. Nordhaus estimates costs and benefits to agricultural output will balance (i.e., there will be no net impact), at $\$ 10$ billion per year. This figure reflects an EPA (1989a, 1989b) estimate, though Nordhaus aiso reviews studies conducted by the National Academy of Sciences (1983) and Kane, Reilly, and Tobey (1990). The EPA estimate is optimistic, for it assumes a greater carbon fertilization effect than will be realized with a doubling of carbon equivalent. Cline tempers EPA's estimate to account for a lower carbon fertilization effect. Further, based on analysis by Rind et al. (1990), Cline includes the costs from increased incidence of severe drought. Cline's more pessimistic agricultural damage costs are $\$ 8.6$ billion for the 1981 breakilown of the economy.

Both analysts cite EPA (1989b) to justify their divergent valuations for energy costs. Nordhaus uses EPA's lower bound estimate for GNP growth to predict increased cooling

${ }^{8}$ As Box 3-1 illustrates, this assumption can be challenged on the grounds that shock disturbances to certain sectors of the economy can reverberate, initiating non-linear impacts on other sectors. An extreme example is the agricultural sector; although agriculture comprises less than 5\% of the GDP of most industrialized countries, a dramatic reduction in output might substantially impact the general economy. 
requirements with global warming. He then uses professional judgement to assume space heating requirements will decline by $1 \%(1989 \text {, Table } 4)^{9}$. Cline begins with EPA's mid-range estimate of cooling requirements for a $3.7^{\circ}$ Celsius warming by 2055 . Because IPCC estimated warming for a doubling of carbon equivalent is $2.5^{\circ}$ Celsius, Cline scales the EPA cost estimate down to reflect more moderate temperature increases, though his cost estimate is still nearly three times the Nordhaus estimate. Cline uses professional judgement to assume non-electric heating costs will be reduced $5 \%$. Overall, Cline anticipates energy costs will increase $\$ 4.9$ billion, while Nordhaus anticipates about a $\$ 0.5$ billion increase.

Perhaps as interesting as their direct damage cost estimates are the references Nordhaus and Cline make to damage costs excluded from their calculus. Costs and benefits that are difficult to quantify, like species extinction, loss of human life, cultural degradation, and joint benefits from pollution reduction such as lower health costs are not included in Nordhaus' calculations. Nordhaus acknowledges that non-marketed goods "...escape the net of the national income accounts and might affect the calculations" but also finds that "[some] people will place a high moral, aesthetic, or environmental value on preventing climate change, but I know of no serious estimates of what people are willing to pay to stop greenhouse warming" (1991, p. 44). Despite the difficulties of quantifying impacts that are either non-market or non-anticipatable, Cline includes such impacts in his cost calculus. Cline estimates the potential costs of changes in recreation, water, species loss, migration, hurricane damage, urban infrastructure, health and welfare, and forestry, finding them to be cumulatively greater than the costs of climate change on agricultural output.

Cline finds the cumulative costs of a doubling of carbon equivalent to be five times the direct estimate of Nordhaus. Cline also examines the long-term impact of global warming, contending that with a geometric damage function, long-term impacts will prove quite costly. The key differences between Cline and Nordhaus are: (1) Cline uses a geometric and Nordhaus a linear damage function; (2) Cline includes non-market indicators while Nordhaus focuses on impacts with ready market indicators; (3) Cline examines both short- and long-term damages, while Nordhaus examines damages for a doubling of carbon dioxide equivalent.

The Nordhaus and Cline damage cost analyses apply to the particular scenarios they construct, though there is no assurance that the future state of the world in an enhanced atmospheric greenhouse will reflect their scenarios. Further, the simplifications necessitated by monetization procedures preclude full social costing, and an automatic bias towards market-based measurement is the result. Cline's inclusion of more intangible damage costs like health and recreation allows for more sophisticated scenario development, but there is little assurance that the scenario he constructs is more realistic than Nordhaus's. The scenarios are artifacts that allow analysis within the damage cost framework, but are not all-inclusive nor necessarily reflective of the future.

${ }^{9} \mathrm{EPA}$ includes in its estimate electricity savings from reduced heating requirements, so the Nordhaus estimate double-counts this savings in heating costs. 


\section{Conclusions}

Ideally, monetizing the damage costs associated with climate change allows analysts to compare dissimilar impacts in a commensurable framework. The monetization exercise lays the foundation for the subsequent evaluation process, whereby policy-makers can make informed decisions about policy trade-offs. In practice, full economic commensurability is an unrealizabie goal; asymmetrical impacts, uncertainty, irreversibility, uniqueness of certain environmental resources, and unknown but potentially catastrophic outcomes disallow its attainment. In the complicated, uncertain field of predicting and monetizing global warming impacts, it is important that damage cost analysis be made as rigorous as possible. It is also important to recognize the inherent limitations of such analysis, the potential for misplaced concreteness, and the influence of values and world views in shaping the damage function.

Valuation exercises are information intensive, and where information requirements exceed capabilities, there is ample room for analytical subjectivity. The degree of subjectivity is evidenced by the range of cost estimates calculated by Nordhaus and Cline for a doubling of carbon dioxide equivalent. Nordhaus and Cline construct alternative climate change scenarios that reflect professional judgment, values, and world views. While both scenarios are consistent with the emergent facts of climate change, they do not capture the full range of relevant impacts and possibilities. The probability that a particular scenario will result cannot now and may never be derived scientifically. The Cline and Nordhaus studies can best be categorized as two scenarios among a host of conceivable futures. The damage costs they derive are reflections of cognitive factors that govern their selection of scenarios among the innumerable choices possible.

The main criticism we can levy against Nordhaus and Cline is that they give undue weight to the robustness of their analysis. Low probability, high risk events representing the tail of the distribution of effects are excluded from the calculus. Just as the emergence of the ozone hole eluded the ability of atmospheric scientists to predict, so may our scenarios of future climatic changes be inadequate. Climate science indicates it would be rash to rely wholeheartedly on "best guess" scenarios, which ignore the potential for catastrophic event.

Quantifying impacts is a value-laden exercise, made more subjective when impacts are uncertain and there is a time lag between release and impact. The analyst's point of reference will determine if and how an impact will be valued. As Dahlman (1979, p. 156) writes, "This is not science; it is metaphysics: value judgements and political goals will enter into the determination of whether [damage costs] exist." 


\section{EMISSIONS ABATEMENT: MEASURES AND COSTS}

The emergent facts of climate change presage potentially substantial social costs, warranting some degree of redress through greenhouse gas emission controls. There is a substantial body of research into the costs of implementing such controls, particularly for emissions from fossil fuel. We present here a short survey of the results of the literature and discuss implications of the abatement cost calculus for climate policy; for more thorough review of emissions reduction i otential, technologies, and associated costs, see Krause et al. (1992) and Cline (1992a).

The severity and timing of climate change will depend critically upon the path of emissions over time. If emissions are unmitigated, we may incur substantial, irreversible damages, while taking measured steps to direct the path of emissions may imply a climatic regime to which we can adapt. The cost of emissions abatement will vary with the degree of control imposed, and discussion of the presumed relationship between the two can inform the social debate on prudent emissions targets. Given uncontrolled emissions, the IPCC anticipates the equivalent of a doubling of pre-industrial $\mathrm{CO}_{2}$ levels by around 2025 (1991b, p. xxxi). This scenario assumes few steps are taken to control emissions, that fossil fuel use and tropical deforestation continue unabated, and that less than absolute compliance with the Montreal Protocol occurs. By the year 2100 , carbon equivalent concentrations would be over four times pre-industrial levels.

To stabilize worldwide temperatures at their current levels would require emissions reductions from the 1988 baseline in the range of $50-80 \%$ for carbon dioxide, $10-20 \%$ for methane, 75-100\% for CFCs, and 80-85\% for nitrous oxide (EPA, 1991b, IPCC, 1991b). Such a level of emissions abatement is not feasible in the short to intermediate term, particularly given anticipated growth in energy demand in developing countries and their need for continued economic development. There are, however, many possible abatement targets between the laissez-faire level of uncontrolled emissions and the draconian level of abatement required to sustain current temperatures. Several approaches have been advanced to select a prudent abatement target. The precautionary principle, as advanced by Perrings (1991), argues for safeguards against the risk of severe future costs. Perrings advises caution in the face of ignorance over the probability distribution of outcomes and the magnitude of potential losses. Climate stabilization at a tolerable and presumably mild level of temperature change is an example of a precautionary approach (Krause et al., 1989). Another approach is to implement "no regrets" measures that have obvious pay-back characteristics and positive impacts on the economy even if we ignore climate benefits. This approach holds that the risks of climate change warrant implementation of initiatives that will pay dividends no matter what the future climate, but that bold initiatives should await firmer scientific grounds (Gray and Rivkin, 1991). A final approach advocates that we "wait and see" what happens and that no steps be taken until scientific certainty about the timing, distribution, and severity of future climate change has been established.

A host of elements figures into the calculus of emissions abatement costs: the type of greenhouse gas, the activity that generates it, the available abatement technologies, fuelswitching opportunities, and the macroeconomic impact of taxes and other least-cost emission reduction strategies. This chapter reviews the abatement cost literature by splitting activities into energy and non-energy related groupings. The first section discusses non-energy related activities that generate greenhouse gas emissions, possible control strategies, and wh 
available, associated abatement costs. Because of the dominant role fossil fuel combustion plays in both the radiative balance and in the global economy, the energy sector warrants special attention. Hence, the second part of the chapter discusses the costs of reducing energy-related emissions according to alternative modeling approaches. The final section reviews the approaches to selecting abatement targets (i.e., the precautionary approach, "no regrets", and "wait and see") in the context of the abatement cost calculus.

\section{A. Non-Energy Abatement Options}

According to the IPCC (1991a, p. xx), the anticipated contribution from each of the anthropogenic greenhouse gases to the change in radiative forcing from 1980 to 1990 are: Carbon dioxide (55\%), methane (15\%), chlorofluorocarbons (24\%), and nitrous oxide (6\%). As illustrated in Table $2-1$, the accumulation rate for each gas varies from a low of $.25 \%$ per year for nitrous oxide to a high of $4 \%$ per year for CFCs. There are four types of activities resulting in greenhouse gas emissions: Industrial activities (contributing $27 \%$ of radiative forcing) that release CFCs, other halocarbons and small amounts of $\mathrm{CO}_{2}$ (e.g., cement manufacturing); agricultural production (9\%); land-use changes through biomass burning and deforestation (18\%); and energy production and use (46\%).

Non-energy sector activities contribute $54 \%$ of anticipated radiative potential. Reducing these emissions carries unique difficulties and opportunities, particularly where subsistence level activities are impacted. There is a clear priority for meeting basic needs, including food, minimum energy requirements, and the expansion of economic opportunities in the South, regardless of long-term climate impacts. The potential for greenhouse gas abatement must be tempered with the basic needs constraint.

\section{i. Industry}

CFCs are the dominant greenhouse gases emitted by industrial processes, with an anticipated contribution of $24 \%$ to future climate warming. The industrialized countries are responsible for $95 \%$ of global release (Krause et al., 1989, p. I.3-1), with the current annual rate of atmospheric accumulation at $4 \%$. There are no natural sources of CFCs; all of the CFCs in the atmosphere are the result of human activities. CFC-11 is used in the manufacture of blowing plastic foams, CFC-12 in refrigeration systems, and both are used in aerosols.

CFCs are long-lived gases with about 6000 times the global warming potential of a $\mathrm{CO}_{2}$ molecule. The primary impetus for controlling their emissions, however, has been their role in another environmental problem, the depletion of the stratospheric ozone layer. The emergence of the Antarctic nzone hole lent urgency to efforts to control CFC emissions through international agreement. The Montreal Protocol, as adjusted and amended on June 29, 1990, establishes reduction targets and the eventual phase-out of CFCs and halons. The climate mitigation costs for CFCs are thus essentially zero, as costs may be attributed to ozone layer protection.

\section{ii. Agriculture}

Agricultural systems are believed to contribute $9 \%$ of total carbon equivalent releases of 
greenhouse gases to the atmosphere. Emissions include methane from rice paddies and livestock; nitrogen oxides from fertilizer application; and carbon dioxide from biomass burning. Emissions from the agricultural sector are less handily controlled than, say, CFCs or emissions from energy use. The near-term social goal of meeting subsistence requirements regardless of long-term climate impacts will rightly prevail over less immediate and fundamental needs. Further, the difficulty of quantifying emissions from agriculture obfuscates both the potential for and the costs of emissions abatement. For example, the range of uncertainty for the amount of methane released from livestock and rice paddies is high, at factors of 1.5 and 7 respectively. The large number of small-scale and dispersed agricultural sources adds to the difficulty of reducing emissions from this sector.

Nevertheless, there are abatement activities that can also enhance productivity goals. Over the short term, emissions can be reduced by reducing unnecessary biomass burning, substituting livestock manure for nitrogenous fertilizers, and managing livestock waste and feeding practices to reduce methane generation. Over the long term, the IPCC (1991b, p. 81) finds that it may be possible to reduce methane emissions by $25-75 \%$ per unit of product in dairy and meat production through technological means; to manage rice paddies such that a $10 \%$ reduction can be achieved; and to offset the pressures of increasing population through sustainable agriculture practices. Measures promoting soil conservation, sustainable use of water, and preservation of biodiversity can reduce greenhouse gas emissions in the agricultural sector while also promoting the viability and economy of vital agricultural systems.

\section{iii. Land use changes/deforestation}

Land use changes and deforestation contribute about $18 \%$ of total radiative forcing and between 15 and $30 \%$ of carbon dioxide emissions (IPCC, 1991b, p. 77). The amount of carbon currently stored in forests is equal in magnitude to the stock in the atmosphere, some 700 billion tonnes (IPCC, 1991b, p. 77). The total area of remaining forests is approximately 4 billion hectares, about half tropical and the rest temperate and boreal. Over the course of human existence, about 2 billion hectares have been deforested. $\mathrm{CO}_{2}, \mathrm{CH}_{4}$, and $\mathrm{N}_{2} \mathrm{O}$ are released through deforestation, biomass burning (including fuelwood) and other land use changes. As with agricultural emissions, the uncertainty range for emissions from deforestation is high; a factor of 4 separates the high and low estimates of net $\mathrm{CO}_{2}$ emissions (IPCC, 1991b, p. xxx).

Afforested areas fix on average 5-10 tonnes of carbon per ha per year. Afforestation costs are region-specific; in the U.S., estimates range from $\$ 200$ to $\$ 2000$ per ha, or $\$ 1000$ to $\$ 20,000$ per tonne of carbon (IPCC, 1991b). Marginal costs will vary both regionally and temporally. Costs in the tropics will be lower than costs in temperate regions due to lower wage pressures, greater forest productivity rates, and lower land and materials costs. In order to sequester the current anthropogenic carbon emissions, an area the size of Europe from the Atlantic to the Urals would be required. The IPCC finds that 10-15\% of total annual carbon dioxide emissions could potentially be sequestered through afforestation.

\section{iv. Summary}

In total, non-energy related activities contribute $54 \%$ of anticipated increases in radiative forcing. CFC abatement costs are essentially zero since international efforts to protect the 
stratospheric ozone layer should lead to CFC abandonment within the next decade. Mitigation costs for the agricultural sector are more obscure and are also laden with ethical implications; global food supplies both regionally and world-wide cannot be compromised for the sake of greenhouse gas reduction. Some greenhouse gas mitigation activities can enhance agricultural output, but quantifying the costs associated with such strategies is currently beyond analytical capability. Finally, the cost of afforestation will vary regionally and temporally. Afforestation may result in multiple benefits, with enhanced opportunities for indigenous peoples to sustainably utilize forest resources. Though the abatement costs for emissions from land use changes and agriculture are difficult to quantify, there is ample opportunity to implement activities that carry joint benefits in greenhouse gas emission reduction and in sustainable resource use.

\section{B. Energy Sector Options}

Energy production and use is the dominant anthropogenic source of greenhouse gases, with. $46 \%$ of radiative forcing attributed to this sector in the $1980 \mathrm{~s}$. Thus, opportunities for abatement may similarly carry the greatest radiative impact. Relative to emissions from other sectors, energy-related emissions are the best understood and most readily quantified. Greenhouse gases released from energy processes include $\mathrm{CO}_{2}$ and $\mathrm{CH}_{4}$ from fossil fuel combustion and $\mathrm{CH}_{4}$ from coal mines, oil and gas facilities, solid waste landfills, and biomass burning for heating and cooking. Fossil fuel combustion releases by far the bulk of greenhouse gases attributed to this sector. Each of the fossil fuels has a different carbon content, with coal the "dirtiest" fuel and natural gas the "cleanest" in terms of global warming potential. Table 4-1 provides data on $\mathrm{CO}_{2}$ emissions from fossil fuel combustion. As illustrated, coal and oil contribute about equal amounts of carbon, each releasing over $40 \%$ of the total emissions from fossil fuel combustion.

Table 4-1

$\mathrm{CO}_{2}$ Emissions from Fossil Fuel Combustion in 1988

\begin{tabular}{|r|r|r|r|}
\hline & $\begin{array}{r}1988 \text { Carbon } \\
\text { Emissions } \\
\text { (mn tonnes) }\end{array}$ & Uncertainty & \multicolumn{1}{|c|}{$\begin{array}{c}\text { MT Carbon } \\
\text { per EJ }\end{array}$} \\
\hline Total & 5550 & & \\
\hline Coal & 2300 & \pm 230 & 19.0 \\
\hline Oil & 2300 & \pm 230 & 23.7 \\
\hline Natural Gas & 900 & \pm 90 & 13.7 \\
\hline Gas Flaring & 50 & \pm 5 & \\
\hline
\end{tabular}

Fossil fuel emissions from Oak Ridge 1991 data set; Uncertainty ranges from IPCC

Abatement options include switching from high to low carbon fuels, implementing energy efficiency improvements, and capturing emissions through carbon sequestration. The costs of implementing greenhouse gas abatement strategies are subject to regional constraints; while we have a working knowledge of costs in the North, costs to the South are more speculative. 
Further, asymmetric energy demand and growth patterns in the North and South harken the development of strategies tailored to the specific needs of each.

Per capita fossil fuel use in the industrialized world far exceeds use in the developing countries. The average American uses nearly 12 times more fossil energy than the average resident of a developing country. However, energy growth rates in 1980s averaged $4.3 \%$ per year in the South compared with $.8 \%$ per year in the OECD countries, and the forces of urbanization, electrification, industrialization and population growth point to the continuation of this trend.

An international study on energy use scenarios anticipates that with a doubling of the world's population and quadrupling of gross world product, primary energy use would more than double to 633 exajoules by the year 2025 (Levine et ai., 1991), with most of the growth attributed to developing countries. The link between economic growth and increased energy use has only recently been decoupled in the OECD countries, and this transition has not occurred for the bulk of developing countries where energy use continues to grow more rapidly than GDP. For every $1 \%$ growth in GDP in the developing world, energy use increases by $1.3 \%$ (Levine et al., 1991). Should this trend continue, and should GDP increase at $4 \%$ per year, energy use in developing countries in the year 2025 would be over 5.5 times the use today. ${ }^{10}$

Nonetheless, the potential exists for simultaneously reducing greenhouse gas emissions through efficient energy use and assuring sustainable economic growth in the South. By transferring the resource pool of cost-effective energy-saving options already developed in the OECD countries, considerable energy savings could be achieved. Levine et al. $(1991$, p. 3) find "A vigorous effort to increase reliance on cost-effective investments in developing countries ... could achieve a $25 \%$ reduction in consumption ... This could potentially reduce eventual global warming by $1^{\circ} \mathrm{C} . "$

In the North, the cost of reducing energy-related carbon emissions has been studied extensively. Techniques for reducing carbon emissions include fuel substitution, product substitution to non-energy intensive products, increased labor and capital, and afforestation. There are two approaches to evaluating emissions reductions costs: Top-down and bottom-up. Top-down models focus on aggregate relationships between energy use and economic variables such as consumer income and industrial production. Bottom-up models examine the technological potential for emissions abatement and associated costs of implementation. The two approaches offer distinctive insights into the emissions abatement calculus.

The most prominent top-down modeling approach for carbon emissions abatement is to assess the cost of meeting specified emissions targets through the implementation of carbon taxes. One rationale for carbon taxes is that they provide energy users maximum flexibility in obtaining energy services at the least possible cost. Carbon taxes provide incentives for fuel switching, efficiency improvements, and rewactions in the level of energy-using activities without

${ }^{10}$ Levine et al. anticipate that in the absence of government action, energy use in the developing world would be 3.4 times use today. This assumes a number of structural changes in the end-use sectors and improved energy efficiency. 
the need for extensive bureaucratic intervention.

The impacts of carbon taxes are assessed using intertemporal general equilibrium models that capture the interaction of energy supply and demand with the overall structure of the economy. While the details vary from case to case, each model specifies the costs of producing various forms of energy and the response of energy users to price changes. By simulating the development of the economy in the absence of carbon taxes and then imposing taxes sufficient to achieve specified emissions targets, the models estimate the impacts of carbon taxes on the economy as a whole. The models typically find that the direct impacts of reducing carbon emissions in industrialized countries by $20 \%$ by the year 2010 using tax instruments would include a long-term reduction in economic activity of some $1-2 \%$ relative to the base case (Manne and Richels, 1992; Jorgenson and Wilcoxin, 1991).

This figure is based on the assumption that carbon tax revenues would be returned to consumers as lump-sum transfers. This assumption, however, is unrealistic since the substantial revenues raised by a carbon tax would provide governments with flexibility in meeting their overall financial commitments. If, for example, the revenues were used to reduce the levels of distortionary taxes on labor and capital investment, the income losses associated with a carbon tax would be substantially reduced. A review of four recent models of the U.S. economy is instructive on this point (Shackleton et al., 1992). If carbon tax revenues were used to fund investment tax credits, one model found that raising the carbon tax to $\$ 40 /$ tonne by 2010 would have no effect on national income, while two others found that GNP would increase by over 3\% relative to the unconstrained case. Only one model indicated that the imposition of a carbon tax would reduce GNP under these conditions; the projected reduction was $0.7 \%$. On balance, then, the carbon tax literature shows that taxes could have either positive or negative impacts on economic growth. The issue hangs on the coordination of carbon taxes with other aspects of economic policy.

In a world of perfectly rational producers and consumers and perfectly functioning markets, a carbon tax would lead individuals to reduce carbon emissions at the least possible cost. In reality, markets are far from perfect, and a strong case can be made that there are many opportunities to reduce carbon emissions through the implementation of energy-efficient technologies and save money doing it. A careful examination of markets for energy-using goods indicates that there are many barriers that impede the adoption of energy-efficient technologies. Consumers, for example, are often unable to observe the energy efficiency of a building, appliance, or vehicle prior to sale; manufacturers thus have an incentive to produce goods with low purchase prices but unnecessarily high energy use (Howarth and Andersson, 1992).

The existence of market barriers to energy efficiency is substantiated by various bottom-up models that review the technological and economic potential for energy efficiency improvements. A recent review by the U.S. National Academy of Sciences (1991) found that the implementation of technologies that are cost-effective at today's prices could reduce the carbon intensity of the U.S. economy by some $40 \%$ over the long term. Given the slow stock turn-over rate for certain technologies, the achievement of this potential would take time (approximately 10 years for most appliances and cars; 20 years for refrigerators; and 50 years for buildings). If this improvement could be achieved over the course of 20 years, however, the annual rate of change would come to some $2.5 \% / y r$. Historical trends and forecasts of future developments point to improvements 
of only $0-1 \% / y r$ in the absence of price changes or policy interventions. This reality suggests. a role for regulatory measures such as stricter building codes and appliance and vehicle efficiency standards to achieve cost-effective reductions in carbon emissions. If they were well designed, such programs would yield net cost savings and reduce the level of a carbon tax required to achieve specified emissions targets.

Top-down and bottom-up models are complementary approaches to evaluating the abatement cost calculus. Since top-down models do not currently allow for changes in the degree of technical response with increasing carbon taxes, bottom-up models provide indication of technical response potential. The models suggest that a reduction of $20 \%$ of 1990 carbon levels can be achieved in industrialized nations without incurring substantial cost by the year 2010 .

\section{Implications of the Abatement Cost Calculus}

Controlling emissions from agriculture and forestry is a difficult task. The large number of dispersed and small-scale sources and ethical issues relating to subsistence activities obfuscate the potential for inexpensive emissions control. The greatest potential for emissions control is in areas where abatement activities enhance productivity (e.g., soil conservation practices). Currently, little data on abatement costs exist for these sectors, particularly in the South. The area with both the greatest radiative impact and the greatest potential for emissions reduction is in the energy sector. A review of $\mathrm{CO}_{2}$ abatement studies for the OECD countries indicates that low- to no-cost measures are available to reduce carbon emissions and that impacts to the economy of a $20 \%$ reduction by 2010 are anticipated to be no more than $1-2 \%$ of GNP with lower costs achievable through proper coordination of policy response.

In light of this abatement calculus, we can now comment on the three approaches to setting abatement targets: "wait and see," "no regrets," and precautionary (climate stabilization). The "wait and see" strategy we readily abandon as inconsistent with empirical cost evidence. Since there are strategies that both bottom-up and top-down modelers find to be cost-free, the "wait and see" approach appears a particularly listless and irresponsible response. "No regrets" strategies appear to be more consistent with the cost calculus. Efforts to "get the prices right," standards to improve energy efficiency where market failures are demonstrated, and other activities that assure economic retums provide joint benefits to climate and economy. "No regrets" strategies thus provide minimum response, a baseline from which more aggressive strategies, like climate stabilization, may evolve. This final approach is the most vigorous, contending that the fundamental error in the conventional debate over the affordability of warming prevention is the failure to evaluate the full societal costs of greenhouse gas emissions (Krause et al., 1991). Climate stabilization provides insurance against the risks of global warming, and proponents contend that precautionary investment in least-cost strategies will provide long-term climate relief before "the cure proves worse than the ailment" (Krause et al., 1991 , p. I.1-4). The goal of climate stabilization is compatible with the recently signed Global Warming Convention.

In order to discuss the trade-offs between "no regrets" and climate stabilization, we must have a normative framework through which valuations can be evaluated. The next chapter, "Normative Criteria for Climate Policy", provides this necessary bridge to policy-making. 


\section{NORMATIVE CRITERIA FOR CLIMATE POLICY}

The preceding chapters outline the emergent facts of climate change - the state of knowledge concerning the relationship between greenhouse gas emissions and future climatic conditions, the potential impacts of climate change on physical and biological systems, speculation concerning the translation of those impacts into socioeconomic terms, and the cost of greenhouse gas mitigation measures. A key fact emerging from this assessment is the asymmetric distribution of impacts between regions and over time. While living persons, particularly in the North, enjoy the benefits of activities that generate greenhouse gas emissions, climate impacts will fall principally on members of future generations and may disproportionately affect the South. Although the existing information base on the impacts of climate change is rich with the insights of many disciplines, these impacts are and will remain uncertain with the potential for either manageable or catastrophic change.

The emergent facts taken alone are an insufficient basis for collective action. A normative framework is also required to set those facts into perspective so that we may move from "is" to "ought." The goal of normative criteria is to operationalize some set of ethical values. We therefore need to recognize how values impact both our choice of planning criteria and the quantification techniques we adopt. A number of general approaches have been proposed to address the problem. We examine three alternatives: cost-benefit analysis, social welfare analysis, and the principle of sustainable development. Given the inherent uncertainties and intertemporal nature of the problem, each approach should be evaluated based on its treatment of intergenerational equity and robustness in the face of pervasive uncertainty.

The first approach - cost-benefit analysis - is rooted in the concept of economic efficiency, according to which a policy option would lead to improved social conditions if it benefitted at least some individuals while leaving none worse off. As we shall see, cost-benefit analysis is blind to questions of equity since there may exist a great many efficient social states with very different implications for the distribution of welfare between contemporaries and between present and future generations. Although in theory cost-benefit techniques may be extended to allow for uncertainty, in practice the implied information requirements preclude full operationalization. Together, these eventualities limit the usefulness of this approach to the analysis of climate policy.

A second approach is to postulate the existence of an explicit "social welfare function" to directly compare alternative states of affairs. While this approach could in principle cope with issues of uncertainty and equity, it too runs against significant obstacles. The condensation of social values into a well-defined welfare criterion has eluded analysts for well-known theoretical and practical reasons. In its stead, a number of functional forms have been utilized for the presumed social welfare function in studies of optimal intergenerational allocation. While these specifications permit the exploration of the consequences of alternative ethical frameworks, they will be a good guide to policy only if they correspond to prevailing conceptions of social ethics.

Finally, we consider the principle of sustainable development as a guide to intertemporal and intergenerational choice. A precise definition of sustainability has eluded resource policy analysts, and the principle lacks the authority of a fully articulated planning criterion in the absence of further elucidation. As a result, determining the principle's operational implications 
is sometimes problematic. The basic thrust, however, is that a development program is sustainable if it allows the present generation to meet its needs without compromising the welfare of future generations (WCED, 1987). According to one perspective, sustainability may be interpreted as a distributional criterion that rules out development paths that yield declining living standards over time (Pezzey, 1989). The extension of this approach to allow for uncertainty is of obvious importance in determining its implications for climate policy.

This chapter explores the ethical foundations of the various welfare criteria that have been applied in the analysis of climate policy (see also Brown, 1992; Broome, 1992). We outline the theoretical and practical difficulties associated with the application of cost-benefit evaluation and social welfare analysis to the issue under discussion and lay out the argument for the sustainability approach. The final chapter examines the operational consequences of the sustainability criterion and defines an integrated approach to climate policy analysis.

\section{A. Cost-Benefit Analysis}

Cost-benefit analysis is rooted in a simple but compelling ethical proposition. By the doctrine of Pareto efficiency, a proposed policy change will lead to an improvement in social conditions if it benefits at least some members of society while leaving none worse off. Actual policy changes generally benefit some individuals but harm others, so this maxim would appear on the surface to have limited relevance to the real world. Suppose we define the net monetary benefit accruing to each individual as his or her net willingness to pay for a proposed policy change. If we assume that people are the best judges of their own well-being and that they are economically rational, a policy change will improve their welfare if they would be willing to pay a positive sum of money to put it into effect. Conversely, they would be injured if they would be willing to pay to prevent implementation of the policy. If the summed positive benefits accruing to the winners are greater than the summed "costs" or negative benefits incurred by the losers, then in principle the winners could compensate the losers so that the welfare of all individuals could be improved. Policy proposals that satisfy this standard, sometimes termed the Kaldor-Hicks criterion, are termed potential Pareto improvements and may in principle be identified using cost-benefit analysis.

A broad range of techniques have been devised to measure the net willingness to pay for proposed policy changes (Johansson, 1987; Johnson and Johnson, 1990). In the simplest case, net benefits are measured by multiplying the change in the availability of each affected good by its price, assuming that no price changes are induced by the policy. Where the change is non-marginal so that not only quantities but also prices are affected, the appropriate indicator is the change in "social surplus", approximated in competitive markets by the area bounded by the market supply and demand functions between the initial and final quantities of the good (Willig, 1976).

A pervasive problem in cost-benefit analysis is the aggregation of costs and benefits that accrue at different points in time. Generally speaking, future benefits are worth less than those of the present since a dollar today may be invested to yield 1.03 dollars next year given a 3\% interest rate. In neoclassical models of intertemporal equilibrium under perfect foresight, the interest rate constitutes a measure of an individual's marginal preference for consumption in sequential periods (Howarth and Norgaard, 1992). This fact does not imply that people prefer 
the present to the future in any abstract sense - only that they optimize their consumption streams in a world of investment opportunities.

To express present and future benefits in comparable present-value units, net benefits that are realized $t$ periods from the present are discounted by the factor

$$
\delta_{t}=\prod_{\tau=1}^{t} \frac{1}{1+r_{\tau}}
$$

where $r_{t}$ is the interest rate at date $t$ and $\delta_{0}=1$. In the special case where the interest rate is constant over time so that $r_{t}=r$, this formula reduces to the more familiar $1 /(1+r)^{t}$. Suppose that $C_{t}$ and $B_{t}$ are the flows of monetary costs and benefits realized at time $t$ as a result of the proposed policy change. Then the net present value (NPV) of the net benefits yielded by the proposed policy change is given by

$$
N P V=\sum_{t=0}^{T} \delta_{t}\left(B_{t}-C_{t}\right)
$$

where the current date is normalized to $t=0$ and $T$ is the final date at which the policy has economic impacts. If this quantity is positive, then the policy change constitutes a potential Pareto improvement and is said to yield net positive benefits in the sense that the policy could in principle be implemented along with appropriate income transfers so that all members of society would be rendered better off. It is well-recognized, however, that a potential Pareto improvement need not constitute an actual Pareto improvement. If policy implementation benefits some individuals at the expense of others and no compensation follows, the logic supporting cost-benefit analysis breaks down. Potential Pareto improvements constitute unambiguous opportunities for improved social welfare only if the "losers" are duly compensated.

The methodology described above is useful in evaluating the net benefits of a particular policy alternative relative to an assumed baseline. In general, a continuum of possible policies exists, and the efficiency criterion mandates the selection of the option that maximizes the NPV expression. Suppose, for example, that the policy problem is to choose an efficient level of greenhouse gas emissions in a given year $(t=0)$. Let $\mathrm{MB}_{0}$ be the marginal benefit of current emissions and assume that current emissions add $\alpha^{\mathrm{l}}$ units to the period $t=0, \ldots, \mathrm{T}$ stock of greenhouse gases where $0<\alpha<1$. This specification allows for the removal of greenhouse gases from the atmosphere via biogeochemical processes. If the greenhouse gas stock imposes a marginal impact of $\mathrm{MC}_{\mathrm{t}}$ on the economy at date $\mathrm{t}$, the marginal impact associated with current emissions is $\alpha^{\mathrm{t}} \mathrm{MC}_{t}$. Maximization of (4) implies the equation of the marginal costs and benefits generated by current greenhouse gas emissions so that

$$
\mathrm{MB}_{0}=\sum_{t=0}^{\mathrm{T}} \delta_{\mathrm{t}} \alpha^{\mathrm{t}} \mathrm{MC}_{\mathrm{t}}
$$




\section{i. Applications to climate policy}

Iden fification of an "optimal" climate policy requires an operational definition of optimality. Environmental economists, following the conventions of their discipline, have focused on costbenefit analysis as the favored normative approach. As Peck and Teisberg $(1992$, p. 1) present the issue,

"Proposed policy responses to global warming have generally been framed in terms of limits on emissions of greenhouse gases, especially $\mathrm{CO}_{2}$. Most sucin proposals seem to be quite arbitrary in character, e.g. limit $\mathrm{CO}_{2}$ emissions to 80 percent of 1990 levels. The very arbitrariness of such proposals raises the question: what is the best path of emissions over time? It is not possible to determine an optimal em isions path without considering both the costs and the benefits associated with reductions in $\mathrm{CO}_{2}$ emissions."

As we discussed in Chapter III, damage estimation remains in a primitive state, and the application of cost-benefit techniques to climate policy analysis requires reliance on uncertain or even arbitrary numbers. Nonetheless, provisional attempts to apply cost-benefit analysis are worthwhile, both because they provide a first cut in identifying an economically efficient policy response and because they point to the key uncertainties in our understanding.

One cost-benefit study has gained particular attention in the literature: the work of Nordhaus (1991b). This study does not fully conform to the dynamic rule for identifying an efficient ievel of greenhouse gas emissions embodied in equation (5). Nordhaus limits his analysis to the consideration of "resource steady-states" - paths where the level of greenhouse gas emissions and the stock of greenhouse gases in the atmosphere are constant into the infinite future. While the steady-state assumption is useful because it sharply reduces the difficulties of computing numerical solutions, its relevance to policy analysis can be questioned on at least two grounds. First, in today's world the atmospheric greenhouse gas stock is increasing at a rapid rate. To calculate the extent to which current emissions should be curtailed requires explicit examination of this fact.

A second issue is perhaps more $f$ undamental. Over the long term, there is no guarantee that an efficient path would converge to a constant level of greenhouse gas emissions. Indeed, there are strong $a$ priori reasons to believe that such a result would not arise, at least not with positive emissions of carbon dioxide from fossil fuel combustion. This is because the total stock of fossil fuels is finite and would be exhausted over the course of a few centuries at current use rates. The question Nordhaus poses might be phrased as follows: What level of fossil fuel use would be efficient if it could be extended into the infinite future? The real-world policy question, however, is how ' we should manage the (dynamic) transition from our current energy regime to one less centered on carboniferous fuels.

That said, the Nordhaus analysis constitutes an interesting thought experiment: By how much would 'ong-term greenhouse gas emissions need to be reduced to achieve a Pareto efficient resource allocation, assuming the economy converged to a resource-steady state and that fossil fuel use were not limited by cumulative resource constraints? Nordhaus answers that reducticns ranging from near zero to about one-third could be justified on the grounds of economic efficiency under his assumptions regarding the costs and benefits of greenhouse gas mitigation 
strategies.

As we saw in Chapter III, the Nordhaus study assumes a linear relationship between greenhouse gas stocks and climate impacts. Moreover, his estimates of the expected costs of climate change are conservative and omit many potential costs - for example, the potential threat of catastrophic change. An alternative assessment is offered by Cline (1992a, 1992b), who assumes that damages rise geometrically with the greenhouse gas stock and that the damages associated with a doubling of carbon-equivalent are some five times the direct estimate of Nordhaus, who adjusts his own cost estimates upwards to account for unmeasured impacts. Unlike Nordhaus, Cline does not seek to identify an optimal level of emissions abatement but instead limits himself to the comparison of two alternative policy regimes: a laissez faire case of unconstrained emissions, and an aggressive abatement policy where worldwide carbon emissions are reduced to a permanent limit of 4 billion tonnes per year in comparison with baseline emissions of 6.7 billion tonnes in 1990 and 14 billion tonnes in 2050 . Cline's analysis is explicitly dynamic and allows for uncertainty through the specification of low-, mid-, and high-damage scenarios. He finds that the abatement policy is economically warranted provided that decision makers are risk averse, attaching a relatively high weight to unfavorable outcomes in the cost-benefit calculus.

\section{ii. Cost-benefit analysis and intergenerational equity}

A distinguishing characteristic of cost-benefit analysis is its marriage to the baseline. All of the variables that go into a cost-benefit calculation - the cost of reducing GHG emissions, the associated environmental benefits, and the discount rate - are reflections of anticipated economic conditions. The future path of the economy is not, however, fixed in stone but is instead of matter of collective choice. Should we as a society use the resources at our disposal to maximize our own selfish gratification without regard to the welfare of future generations? Should we act so as to ensure that the life opportunities of our children and grandchildren are equivalent to or better than our own? Either choice is possible and either may be pursued with consummate economic efficiency. Yet the efficient balance between the costs and benefits of greenhouse gas emissions might vary sharply under the two scenarios.

Suppose, for example, that climate impacts vary in linear proportion with world income. Then strong economic growth would raise the damages caused by greenhouse gas emissions relative to a low-growth scenario at each point in time. As we noted above, the discount rate appropriate for use in cost-benefit analysis is equal to the marginal return on capital investment in the absence of market distortions. Economic growth is fueled by capital investment, with the rate of capital accumulation involving an equity decision concerning the level of wealth we wish to transfer to fut re generations. Increased accumulation implies a decrease in the marginal return on investment and hence a reduction in the social discount rate. Together, higher impacts and lower discount rates imply that it would be efficient to abate greenhouse gas emissions more aggressively in a high-growth world than in a low-growth alternative.

This argument rests on particular theoretical and empirical assumptions and is rather informal in character. It is possible, however, to illustrate similar results using formal models rooted in the theory of intertemporal general equilibrium. Howarth and Norgaard (1992; see also Page, 1988), for example, showed that cost-benefit techniques may be used to identify 
efficient greenhouse gas emissions profiles in a hypothetical overlapping generations economy. The efficient outcome, however, depends strongly on the degree of caring for the future, with an efficient world of deplorable living standards and high pollutant levels for future generations ours for the choosing should we so desire.

While the details of the Howarth-Norgaard model need not concern us here, a review of its results provides some insight into the subject under discussion. Figure 5-1 shows the levels of key economic variables - per capita consumption, the capital stock, greenhouse gas concentrations, and the social discount rate - for two model runs. The "impoverished future" case assumes an ethical framework in which present society cares little for posterity and thus depletes capital assets and adds substantially to the stock of greenhouse gases. The "sustainable future," in contrast, assumes that the present generation preserves capital goods and environmental quality for the sake of future generations. In each case, cost-benefit criteria are applied to identify an efficient greenhouse gas emissions profile. The two differ in the transfers of assets that are effected from one generation to the next, equivalent to transfers of wealth from the rich to the poor motivated by concerns about social justice (Bator, 1957). 
Figure 5-1

Alternative Future Worlds

(a) Impoverished Future

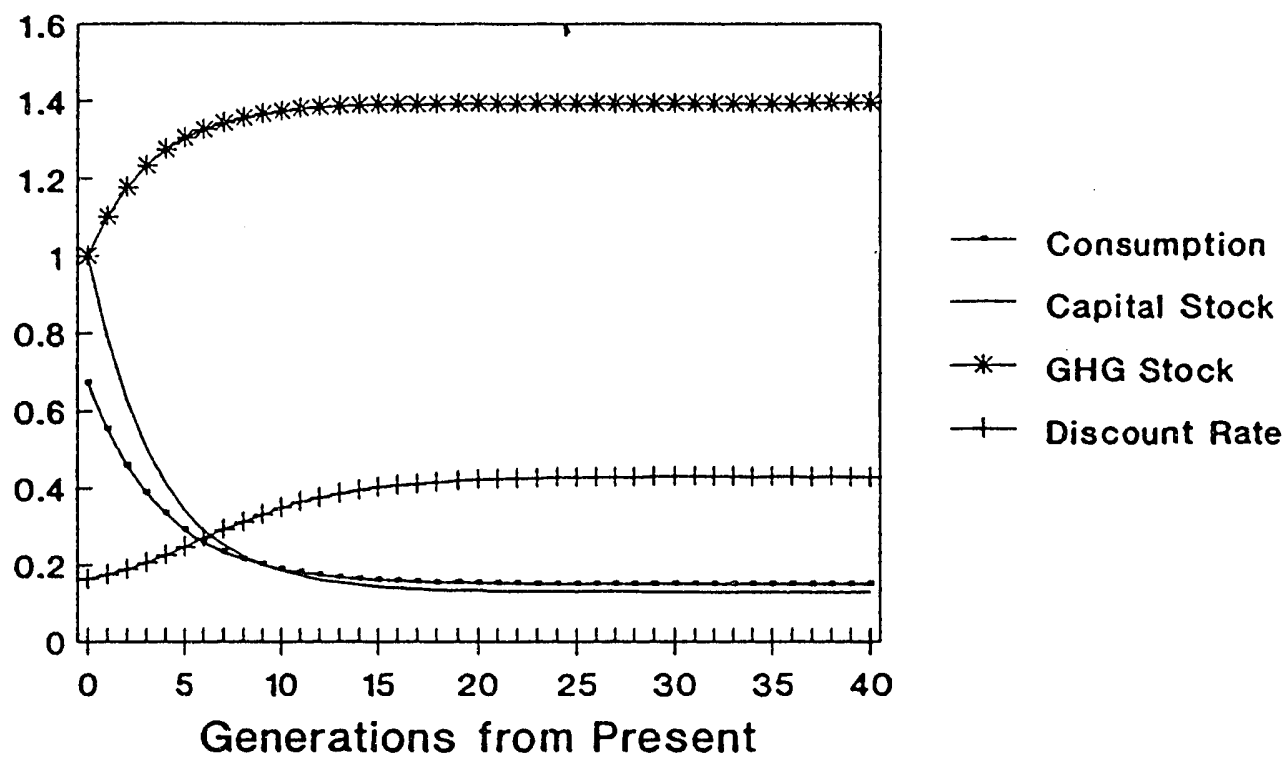

(b) Sustainable Future

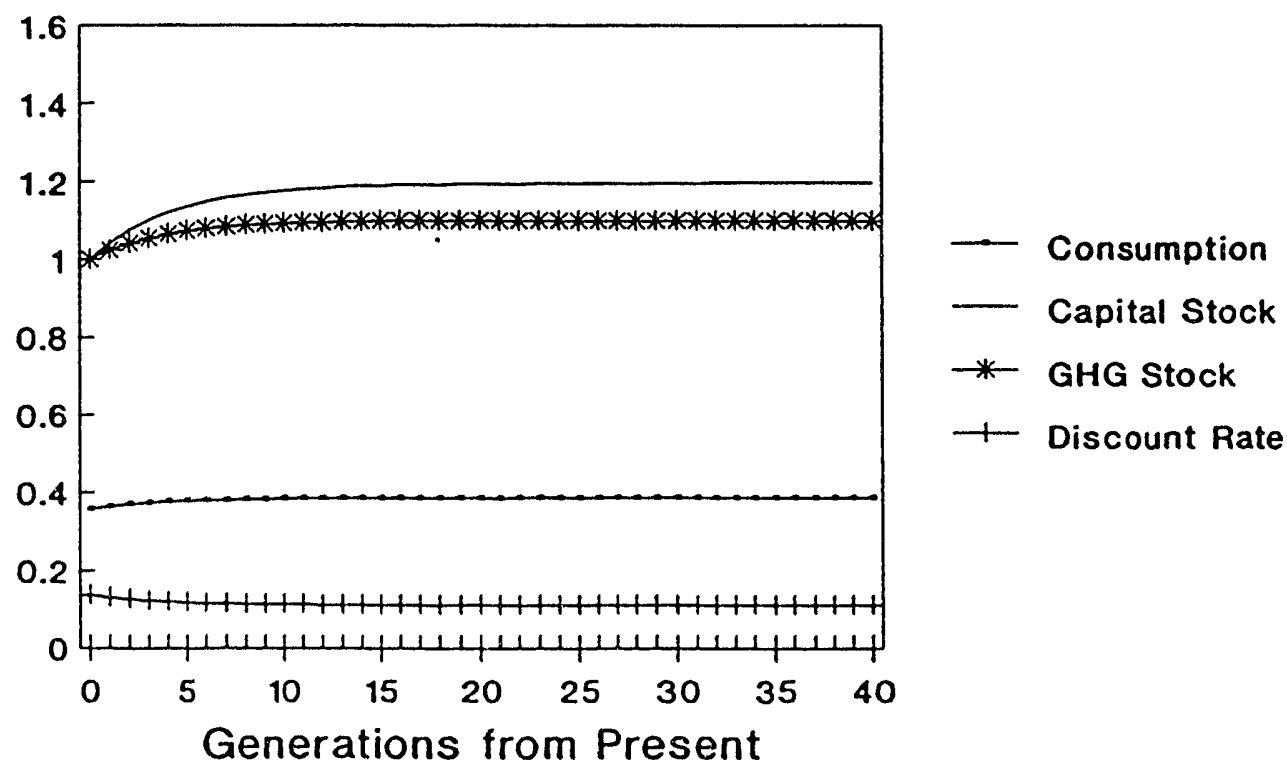


The use of cost-benefit procedures will lead to an efficient climate policy response only if the analyst correctly anticipates the future course of the economy. This represents a logical paradox since the "all else equal" assumptions of partial analysis are of limited relevance in an environment where all policy variables are subject to simultaneous choice. As Dasgupta and Heal $(1979$, p. 257$)$ pointet out, in economic future "can be intertemporally efficient and yet be perfectly ghastly" if it denies future generations the physical and cultural conditions required too sustain a satisfactory way of life. These facts should give us pause for thought about the use of cost-benefit analysis to identify an "optimal" response to the climate problem in a world where issues of intergenerational equity are at stake.

It is sometimes argued that scientific and technical progress are paving the way to a world of future abundance, obviating the need for worries about intergenerational equity in the analysis and promulgation of public policy. Indeed, the centuries since the Industrial Revolution have been marked by profound improvements in living standards led by fundamental transformations in the interrelationships between technology, social institutions, and the natural environment. But trends are not destiny, and one cannot safely assume that conditions will improve in the future simply because they have improved in the past. Some argue that the trend towards economic progress has already reversed and that today's young people will be unable to match the quality of life achieved by their parents in the absence of policy intervention (Daly and Cobb, 1989). In the United States, median incomes have been stagnant since the early 1970s with reductions for men under age 45 (Levy and Murnane, 1992). The question to ask is as follows: Is the present generation contributing to the technological base and preserving the capital and natural assets required to sustain the future welfare in light of anticipated technological progress and emerging environmental constraints?

We emphasize that we are not technological pessimists who believe that the world is headed for certain disaster. But ours is the power to confer a world of poverty or abundance to the members of future generations. There is no guarantee thai events will turn out favorably in the absence of careful planning regulated by the adoption of suitable planning criteria.

\section{iii. Cost-benefü analysis and interregional equity}

Conventional cost-benefit techniques place equal weight on net monetary benefits that accrue to contemporaries regardless of their relative welfare. This runs against our moral intuition, for many would argue that a dollar spent on the poor yields benefits of greater moral worth than a dollar spent on the rich. In the context of climate change, this issue arises most prominently because of the asymmetric distribution of costs and benefits between the North and South. The individuals most adversely affected by climate change are likely to be residents of low-income nations lacking the means to adapt favorably to changing climatic conditions. Should we attach small monetary values to the catastrophic losses of peasant farmers simply because they lack the wealth required to sustain willingness to pay?

The North has benefitted greatly from the use of technologies that generate greenhouse gas emissions and can arguably afford to take steps towards emissions abatement. The South, on the other hand, has contributed only modestly to the stock of greenhouse gases currently in the atmosphere, and draconian emissions limitations might jeopardize the continued improvement of living standards. Cost-benefit criteria ostensibly imply that emissions reductions should be 
realized wherever they can be achieved at the least monetary cost. Equity considerations, on the other hand, may demand the sharing of burdens to avoid imposing hardship on those already disadvantaged.

In theory, issues of equity could be redressed through the transfer of wealth from rich to poor. The North, for example, could ameliorate poverty in the South through technology transfer and the provision of increased development assistance. Cost-benefit analysis could then be applied to identify opportunities to improve economic efficiency, benefitting North and South alike. In practice, however, disparities of wealth are likely to persist, and maintaining greenhouse gas emissions in the North may take away some future peasants' only valuable asset - the stability and benevolence of nature. Although such transfers of wealth from poor to rich might pass the test of Pareto efficiency, they are difficult to defend on moral grounds.

\section{iv. Cost-benefit analysis and uncertainty}

Analyses of the potential costs and benefits of climate change often focus on expected outcomes, averaging across low and high impact scenarios to obtain an estimate of the most likely sequence of events. Given the great uncertainties associated with climate change, such a focus is not entirely appropriate. Our intuition informs us that fire insurance is a good investment even though we hope and expect that our homes will never burn down. Put another way, individuals will often give up expected benefits to protect themselves against the possibility of large losses.

One approach to cost-benefit analysis under uncertainty is to use ad hoc procedures to adjust expected outcomes for risk. A standard argument is that individuals demand higher expected rates of retum on investments yielding risky benefit streams in comparison with secure investments such as long-term government bonds. Thus cost-benefit analysts sometimes apply high discount rates in evaluating uncertain projects. While such an approach is simple to apply in practice, in theory it is rather objectionable (Wilson, 1982). Theory informs us that a rational investor will demand a high expected rate of return on an uncertain investment if its returns are positively correlated with the return on her/his overall investment portfolio. Conversely, she/he will accept comparatively low (or even negative) expected returns on assets that provide insurance by yielding high returns when the market as a whole turns sour.

The insurance metaphor has frequently been cited as a justification for climate policy intervention. Schelling (1992, p. 8), for example, observed that "Insurance against catastrophes is ... an argument for doing something expensive about greenhouse emissions" (see also Manne and Richels, 1990). In principle, cost-benefit techniques may be used to identify social willingness to pay for such insurance. Suppose as above that a unit of current greenhouse gas emissions contributes $\alpha^{2}$ units to the stock of greenhouse gases $t$ periods into the future. Suppose further that there are $n(t)$ possible outcomes or "states of nature" at date $t$ denoted $s_{\mathrm{i}}$ for $i=0, \ldots, n(t)$. The probability of each state is $\operatorname{Pr}\left(s_{i}\right)$, and the marginal benefit associated with greenhouse gas emissions at time $t=0$ is $\mathbf{M B}_{0}$. If the stock of greenlouse gases imposes the marginal climate impact $\mathrm{MC}_{\mathrm{i}}$ under state $s_{\mathrm{i}}$ at date $\mathrm{t}$, the socially efficient level of emissions is identified by the cost-benefit formula (Howarth, 1991a): 


$$
\mathrm{MB}_{0}=\sum_{\mathrm{t}=0}^{\mathrm{T}} \sum_{\mathrm{i}=1}^{\mathrm{n}(\mathrm{t})} \operatorname{Pr}\left(\mathrm{s}_{\mathrm{t}}\right) \delta_{\mathrm{i}} \alpha^{\mathrm{t}} \mathrm{MC}_{\mathrm{i}} .
$$

The discount factor $\delta_{\mathrm{t}}$ deserves special comment. In theory, this factor varies across time and states of nature, accounting simultaneously for individual preferences concerning both time and risk. Each contingent future is linked to the present by its own state-contingent discount factor. The discount factor depends on individuals' risk aversion and on their relative well-being at sequential dates and under alternative states of nature.

It is clear that enormous quantities of information would be required to rigorously evaluate the costs and benefits of greenhouse gas emissions under uncertainty. We would need to know the complete range of possible future states, including their statistical probability, marginal climate impacts, and implications for human welfare. In order to evaluate this equation, we would need to gauge social preferences regarding time and risk, even for low-probability, extreme outcomes for which we have little hard information to fall back on. A heuristic version of the approach embodied in equation (6) is offered by Cline (1992b), who examines the net benefits of greenhouse gas emissions abatement under three scenarios regarding the relationship between greenhouse gas stocks and climate damages: low, medium, and high. Each scenario is assigned a subjective weight based on its probability and the presumed risk aversion of the decision maker. Without denigrating the utility of Cline's calculations, it is not difficult to see that a more rigorous application of cost-benefit analysis under uncertainty is simply inoperational - we cannot fully identify an economically efficient climate policy response.

Where does that leave cost-benefit analysis as an approach to understanding climate policy? We can use crude information to get some feeling for the expected impacts of climate change as well as the probability of extreme change. We can reasonably speculate that society would be willing to spend extra resources to mitigate the threat of potentially catastrophic risks. But the appropriate sum to pay is beyond the reach of economic analysis and thus depends on the exercise of raw value judgements regarding what is acceptable and what is not.

\section{B. Social Welfare Analysis}

The problem of climate change has potentially far-reaching consequences for the distribution of welfare between world regions and between present and future generations, yet cost-benefit techniques are inherently ill-equipped to assess equity concerns. How then should we proceed in the definition of "socially optimal" climate policy? The usual approach to this problem is to posit the existence of a social welfare function as a means of comparing and evaluating alternative social states based on the distribution of welfare across all members of society. Suppose that there are $\mathrm{n}$ members of society, some of whom are members of future generations, and that the well-being of individual $i$ under social state $x$ is represented by the utility function $\mathrm{U}_{i}(\mathrm{x})$. Then a social welfare function may be defined as a function $\mathrm{W}(\mathrm{x})=\mathrm{W}\left[\mathrm{U}_{1}(\mathrm{x}), \ldots, \mathrm{U}_{\mathrm{n}}(\mathrm{x})\right]$ that captures the general well-being of society as a function of individual utility levels.

Given a particular social welfare function, the problem of identifying a social optimum is in principle well-defined. The analyst needs merely to identify the set of policies that maximizes the welfare function subject to existing technological and social constraints. If we assume that 
social welfare always improves when one person's condition improves while no other is left worse off, then social welfare will be maximized by a Pareto efficient allocation.

A number of conceptual and practical difficulties, however, constrain the usefulness of this approach. Evaluating social welfare requires the measurement of individual utilities, but both theory and practice suggest that this is generally impossible. For the concept of social welfare to be applied to the problem of climate change, the utility functions of members of future generations must be known. But while we may hazard to guess the nature of future preferences, can we truly say that the preferences of the unborn are knowable to members of the current generation who must render decisions regarding intertemporal climate policy?

A second difficulty also demands consideration. Even if utility levels could be operationally defined, how would the social welfare function to be used in intergenerational planning be established? Different individuals may havedifferent perceptions of social welfare, and without unanimity the existence of a welfare function may be problematic. Arrow (1970), for example, has shown that it is impossible to find a rule for aggregating individual preferences into a complete social preference ordering that simultaneously satisfies four seemingly plausible restrictions (see Sen, 1970, pp. 41-6):

(1) the aggregation rule must not depend on the particular nature of individual preferences;

(2) if state $A$ is preferred to state $B$ by all individuals then $A$ must be socially preferred to $B$;

(3) the relative social ranking of states $A$ and $B$ must not depend on whether a third alternative, $C$, is available;

(4) the preferences of a single individual must not completely determine social preferences.

It is also widely recognized that majority-rules voting procedures generally do not give rise to a consistent set of social preferences that might be represented by a social welfare function. Suppose, for example, that there are three individuals $(1,2$, and 3$)$ and three policy options $(A$, $B$, and $C$ ). Person 1 favors $A$ over $B$ over $C ; 2$ prefers $B$ over $C$ over $A$; and 3 favors $C$ over $A$ over $B$. Which option would they choose if the options were compared pair-wise using a majority-rules voting procedure? It is not difficult to see that $A$ would prevail over $B$ and $B$ would prevail over $C$, so logically $A$ should prevail over $C$ as well. In fact, however, $C$ would beat $A$ by two votes to one in a direct democratic test, so this institution does not give rise to a consistent ordering that could be used to compare the social desirability of the competing options (Sen, 1970, p. 38).

These difficulties imply that the social welfare approach is not a fully operational guide to intertemporal choice. Nevertheless, policy analysts have often posited the existence of social welfare functions in order to pursue conceptual arguments or to examine the distributional consequences of particular ethical frameworks. In light of the above, there appear to be three competing options concerning the specification and use of social welfare functions: 
(1) simply assume that a social welfare function exists that represents the preferences of some relevant agent such as a "social planner";

(2) define a social welfare function that corresponds to a particular ethical theory concerning the distribution of welfare across individuals;

(3) reject the notion that a social welfare function exists and search for weaker but operational distributional criteria.

Each of these strategies has been employed in the analysis of climate policy. But whichever course is chosen, it should be clear that a definition of "social optimality" must be rooted ultimately in prior value judgments so that there can be no value-free approach to the problem of "optimal" intertemporal resource allocation.

\section{i. The additive separable welfare function}

To apply the social welfare approach to the analysis of climate policy requires a fully specified welfare function and a model of reality expressing the well-being of present and future persons as determined by policy decisions. Under this approach, climate policy is not determined in isolation. Instead, all aspects of policy, including capital investment and the provisioning of assets to future generations, are chosen simultaneously to achieve the best possible result.

The most commonly used welfare criterion in the optimal planning literature is the additive separable social welfare function. Suppose that there is a sequence of generations $t=0, \ldots, T$ with respective utility levels $\mathrm{U}_{0}, \ldots, \mathrm{U}_{\mathrm{T}}$. The utility of a given generation may be construed as the utility of a representative individual from the generation or alternatively as a welfare index for the generation as a whole. Of course, such a specification abstracts from questions regarding the distribution of wealth amongst contemporaries. According to this framework, the additive separable welfare function is commonly written in the form

$$
\mathrm{W}=\sum_{\mathrm{i}=0}^{\mathrm{T}} \mathrm{U}_{\mathrm{i}} /(1+\beta)^{\mathrm{t}}
$$

The value of the discount factor $\beta$ is a matter of some controversy. It is usually assumed that $\beta \geq 0$ so that the welfare of future generations is weighted less heavily than that of the present. But if $\beta$ is set equal to zero, then present and future welfare is equivalent from the perspective of social welfare. A number of authors have argued for a zero discount factor on the grounds that fairness to the future requires equal treatment for each generation. Ramsey $(1928$, p. 543), for example, held that discounting the welfare of future generations is an "ethically indefensible" practice that "arises from the weakness of the imagination". Similarly, Pigou (1932, p. 25) declared that discounting "implies only that our telescopic faculty is defective". And Harrod (1948, p. 40) asserted that discounting is "a polite expression for rapacity and the conquest of reason by passion".

Howarth and Norgaard (1992) examined the implications of the additive separable welfare function for an abstract intertemporal economy confronting climate change. The choice of a 
high discount factor implied deterioration in environmental quality and living standards over time, while the use of a low but positive discount factor gave rise to a sustainable outcome. This conclusion echoes the well-known result that utility discounting does not in itself imply any unfairness to future generations (Blanchard and Fischer, 1989).

It is important to note that the discounting techniques embodied in cost-benefit analysis are logically distinct from the additive separable social welfare function and do not necessarily imply that the welfare of future generations counts less heavily than that of the present. The presentvalue criterion stems directly from the definition of economic efficiency and the possibility of earning positive returns on capital investments. While cost-benefit analysis is useful in improving the efficiency of resource allocation, it provides no mechanism for addressing the core issue of social welfare analysis - how to balance the conflicting claims of individuals and social groups. In short, the present-value criterion is not a social welfare function, and cost-benefit techniques provide no means of evaluating changes in "social welfare" properly construed. This important distinction is often blurred in tie literature. Nordhaus (1991b, p. 923), for example, writes that his use of the present-value criterion is helpful in identifying:

"efficient strategies to reduce the costs of climate change. An efficient strategy is one that maximizes overall net economic welfare ..., which includes all goods and services, whether or not they are metered by markets, and includes all externalities from economic activity" [our emphasis].

But just what is the ethical basis of the additive separable welfare function? As Page (1977, pp. 156-7) noted, "This criterion function, or some variant of it, jumps from the page like Athena from Zeus' brow fully grown. In the usual case it is left to the reader to puzzle out the assumptions underlying it, its interpretations and properties." On the one hand, the additive separable form is mathematically tractable and easy to work with in theoretical and applied studies. Furthermore, it bears a superficial resemblance to the net present value criterion so familiar from cost-benefit analysis. Whatever the reason, the additive separable form has gained wide popularity in the literature, although few practitioners have explored the ethical basis of their optimality concept.

\section{ii. The maximin welfare function}

Although the additive separable form dominates the literature on optimal intertemporal planning, its limitations as an expression of social values regarding the distribution of welfare between present and future generations has led to the exploration of alternative conceptions of social welfare. d'Arge et al. (1982), for example, examined the consequences of four alternative welfare functions for a simple economy faced by climate change. They found that the choice of an ethical framework has substantial consequences for the decision rule used to identify the optimal level of greenhouse gas emissions.

Perhaps the strongest objection to the use of the additive separable form in intergenerational welfare analysis is that it permits the living standards of future generations to be reduced to very low levels provided that the benefits to the present generation are sufficiently great. Spash and d'Arge (1989, p. 91) argued as follows: 
"Faced with the decision problem of allocating resources across time, if each individual did not know which generation each would be a part of, they would logically opt for equal treatment among generations."

One of the ethical systems explored by d'Arge et al. (1982) - the maximin social welfare function - by its very design ensures an intergenerationally egalitarian outcome.

The definition of the maximin criterion is rooted directly in an ethical proposition that may be summarized as follows: In welfare comparisons it is the welfare or utility of the worst-off member of society that counts, so any sacrifice that raises the living standard of the poorest individual is justified on distributional grounds (Rawls, 1971). In an intergenerational context, the maximin welfare function takes the form $\mathrm{W}=\min \left(\mathrm{U}_{0}, \ldots, \mathrm{U}_{\mathrm{T}}\right)$ where, as before, $\mathrm{U}_{\mathrm{t}}$ is the utility of the generation living at time $t$.

Several features of the maximin criterion deserve comment. First, the criterion by itself does not require efficient resource allocation. Provided that the welfare level of the worst-off generation is maximized subject to the technical constraints imposed on the economy, it does not matter at all if the welfare of some other generation could be increased through improved economic efficiency. But efficiency may be imposed as a side constraint without any injury to the maximin criterion since for any inefficient allocation there exists some efficient allocation with equal or greater maximum social welfare. It is therefore natural to focus attention on efficient allocations whenever the criterion is applied. Second, the maximin function tolerates any degree of distributional inequality provided that it is impossible to improve the lot of the worst-off generation through the reallocation of resources. But these issues, while theoretical possibilities, are unlikely to arise in applied studies. The combination of the maximin criterion and the standard assumptions of intertemporal optimal development models generally ensures that maximin paths will both be efficient and provide a constant level of welfare to each successive generation (Solow, 1974).

On its face, the maximin criterion implies that it is suboptimal for the present generation to make sacrifices so that future generations may enjoy higher living standards. But if the present generation freely chooses to make such sacrifices, it is unclear from an ethical perspective why it should be bound by the maximin criterion. As we shall see, weaker criteria may be applied to ensure an equitable distribution of resources across generations while allowing some degree of freedom to meet other social objectives.

The application of the maximin rule under uncertainty invokes an interesting question: Is it appropriate to focus on average or expected conditions at each point in time, or should one focus on the subjective welfare of individuals bom under particularly unfavorable circumstances? It is tempting to argue that the individuals born at some future date would have preferences defined across uncertain outcomes. According to this perspective, future generations would be willing to accept some risk if it entailed the probable improvement of living standards. Thus one might focus on an expected welfare approach to intergenerational welfare analysis.

But this line of reasoning runs up against an interesting paradox. As Schwartz (1978; see also Parfit, 1983) argued in a somewhat different context, the identities of future persons depends on the particular circumstances surrounding their births. Seemingly minor alterations 
in living conditions would lead individuals to select different mates, alter the timing of sexual relations, etc. It follows that different sets of potential persons would become actual under alternative contingent futures. A world with catastrophic climate change would be thus be populated by different people than those who would have been born into an environmentally benign alternative. Given this fact, the maximin rule under uncertainty seems to imply that one should maximize the welfare of the worst-off state-contingent generation regardless of the probability that it comes into existence. In a model of exhaustible resource allocation, Howarth (1991b) showed that this focus on worst-case outcomes is consistent with economic efficiency.

The concept of social welfare is rooted in the utilitarian notion that the problem of social planning is a matter of striking the proper trade-off between the welfare of particular individuals or generations. According to this framework, the social welfare function is a mathematical tool that summarizes the distributional preferences of the society in question. The existence of such a function would appear to be indispensable to the problem of.optimal intergenerational planning; for without a welfare function we would have no criterion that defined the concept of optimality. But as we have argued above, the existence and identification of the presumed welfare function pose a number of unsolved theoretical and practical difficulties. As a result, one might reasonably conclude that the concept of social welfare is not operational in the analysis of real-world policy questions.

\section{The Sustainability Criterion}

If we reject the notion of an operational definition of optimal resource allocation, how should we approach the problem of intergenerational planning? The notion of intergenerational equity as it is usually put forth in public debates over environmental policy takes the form of a constraint on the range of intergenerational welfare distributions that are considered ethically permissible rather than a utilitarian definition of optimal distribution. As the criterion is usually stated, economic development should be sustainable in the sense that the utilization of natural resources and the environment by the present generation does not jeopardize the ability of future generations to enjoy a favorable standard of living.

A number of definitions of sustainability and sustainable development have appeared in the literature. Consider, for example, the following selections:

"The sustainability criterion suggests that, at a minimum, future generations should be left no worse off than current generations" (Tietenberg, 1984, p. 33).

"Sustainable development is development that meets the needs of the present without compromising the ability of future generations to meet their own needs" (WCED, 1987, p. 43).

"A sustainable society is one that satisfies its needs without jeopardizing the prospects of future generations. Inherent in this definition is the responsibility of each generation to ensure that the next one inherits an undiminished natural and economic endowment" (Brown et al., 1990, pp. 173-4).

These definitions are rooted in the common principle that present and future generations are 
ethically equivalent although they are not contiguous in time. Hence morality requires that members of future generations have equal or better opportunities than the present generation to live the good life in the same sense that it mandates an equitable distribution amongst the current generation. More so, in fact, since one might argue that while some degree of distributional inequality within a generation might be justified by the relative merits of individuals - the rich may have earned their wealth while the poor may have brought poverty upon themselves - it is difficult to argue that future generations are as a group less deserving than the present. To argue otherwise would be to discriminate against future generations based on the arbitrary happenstance of their birth dates.

Some philosophers, on the other hand, maintain that the present is in general under no obligation to provide a resource-rich world to future generations, or at least that such obligations are very weak. Schwartz (1978; see also Parfit, 1983) has argued that even minor policy changes intended to improve the lot of future generations. would change not only the welfare but also the composition of future generations. Hence we are unable to affect the living standards of a well-defined set of future individuals; instead, we are choosing whether to bring relatively rich or relatively poor individuals into existence. If we take as our assumption that an action is morally mandated only if it benefits some individual who will actually exist, then this argument seems to force the conclusion that beneficence to future generations is not morally required unless the future world is so poor that the lives of future generations are not worth living (Broome, 1992).

Does this argument undermine the ethical basis of the sustainability criterion? Suppose that we define distributional equity as follows: All individuals, both present and future, should have an equal opportunity to pursue their own welfare. According to this criterion, a non-sustainable development program may harm no particular future individual but nonetheless be morally wrong on the basis that it gives rise to an unjust welfare distribution (Green, 1981; Barry, 1983; Dower, 1983; Page, 1983; Brown Weiss, 1989).

Schwartz's line of reasoning is open to another powerful critique. Children are born into this world helpless but for the support of their parents and society generally. Each generation and the next overlap in time, and from a parent's perspective children are not future contingencies but rather facts of day-to-day existence. Most would agree that parents are under a strong obligation to provide their children with life opportunities at least equivalent to their own. For parents and their living offspring are morally distinct only in the happenstance of their birthdates, and it would be unjust for parents to pursue their own selfish interests at the expense of their children simply because their age and familial authority empowered them to do so.

Although the identities of unborn persons remain undetermined, our children will be obligated to their children once they are born and become flesh and blood. Thus our actions must ensure our children a favorable existence while permitting them to honor their obligation to their offspring. By logical extension, this argument defines a chain of obligation between the present and the indefinite future to ensure that living standards are non-declining from generation to generation. We owe it to our children, who will owe it to their children, and so on as far as the mind can see (Howarth, 1992).

But even if sustainability is not deducible from prior ethical principles, it is nonetheless of 
direct policy relevance to the extent that it reflects the distributional values of the current generation. Indeed, the available evidence as reflected by the proclamations of politicians and related indicators of public opinion points to a high degree of concern in the body politic for the welfare of future generations.

The success of the sustainability criterion as a guide to policy analysis depends critically on the translation of these general precepts into operational planning criteria. But while there may be agreement on underlying values, there is considerably less on the implications of these values for intertemporal planning. As Lele (1991) pointed out, the term "sustainable development" will devolve into a meaningless catch-phrase unless it is carefully and operationally defined.

Two major schools of thought have arisen regarding the policy implications of the sustainability criterion. Neoclassical economists have interpreted sustainability as a technical requirement that the utility or welfare of successive generations should be no lower than thai of their predecessors. Pezzey (1989), for example, explored the implications of the sustainability criterion for simple models of intertemporal development, reaching the conclusion that sustainability is a constraint that allows some degree of flexibility in intertemporal planning (see also Riley, 1980). The present generation may choose any path that provides a constant or increasing level of welfare.

This approach runs against some of the same problems confronting social welfare analysis. By what standards, for example, are we to assess the welfare of future generations? One practical approach might be to define sustainability as non-decreasing per capita consumftion. Under this standard, sustainable paths will exist whenever constant consumption paths are technically feasible. But aggregate economic indicators are notorious for their neglect of non-market environmental amenities and the degradation and depletion of natural resource stocks (Repetto et al., 1989). Application of this approach will thus at a minimum require a careful reconsideration of conventional accounting techniques.

A second issue is rooted in the inherent uncertainty concerning the future course of economic development. Policy makers are in fact choosing a probability distribution of potential outcomes, not a single well-defined path for the economy. Thus the question of risk is fundamental to intergenerational resource policy. How far are we willing to go to protect future generations against the possibility of an inhospitable world? As we argued above, the composition of future generations will depend on the state of the world prevailing when they are born. The individuals alive at a particular date under alternative contingent states should thus be regarded as ethically distinct potential generations, and sustainability would seem to require that the welfare of each potential generation be equal to or greater than that of its predecessor. Thus, in a world of uncertainty, the sustainability criterion may require sacrifices on the part of the present generation not only to raise the expected welfare of future generations but also to ensure that living standards are non-decreasing even under the worst of circumstances.

This is a strong supposition that needs to be placed in the context of competing social values. Few would argue, for example, that fifty percent of world income should be diverted to the construction of a planetary defense system to protect against the slight risk that future generations would be left destitute following a collision between the Earth and a large asteroid. On the other hand, the world community has decided to incur significant costs to reduce the 
uncertain threat posed by ozone depletion in the upper atmosphere. At a bare minimum, the sustainability rule suggests the moral obligation to take steps to reduce threats to future generations if so doing does not noticeably impact the subjective welfare of existing persons.

The general equilibrium approach to policy analysis implied by the neoclassical interpretation may be impractical in a world where the sustainability of economic development may depend on the cumulative impacts of numerous specific projects and policy proposals, each of which must be evaluated on an individual hasis under some set of specific guidelines. To hold that the welfare of successive generations should be nondecreasing may be intuitively appealing in an abstract sense. But the development of a set of decision rules sufficient to achieve this objective in the real world policy environment is quite a different matter.

The second approach to the definition of sustainable development attempts to resolve these difficulties to yield practical guidelines for resource and environmental management. The operational focus of this approach is not on the distribution of welfare across generations per se but rather on the sustainability of the conditions required to support a high standard of living into the indefinite future. Thus sustainability implies that we should ensure "the ability of future generations to meet their own needs" (WCED, 1987) or that future generations inherit "an undiminished natural and ecor:omic endowment" (Brown et al., 1990). This approach does not require an exact definition of the welfare of future generations. But it does rule out policy programs that impose substantial risks with regard to future welfare, and it mandates above all that we provide for flexibility as future generations adapt to unforeseen and unforeseeable events.

Adherents to this approach generally advocate the adoption of instrumental values to ensure the sustainability of economic development. Goodland and Ledec (1987), for example, call for the application of safe minimum standards in the design and implementation of development programs. Such standards would set limits on the range of tolerable environmental impacts that could be applied to specific project proposals without resort to exhaustive and often impractical case-specific studies.

Brown et al. (1990) explored the conditions they believe must be fulfilled if economic developrnen is to be sustained over the long-term future: Global population must be stabilized; the efficiency of energy utilization must be raised; energy supply must make the transition from exhaustible and environmentally deleterious fossil fuel technologies to renewable resources such as wind and solar energy; raw materials must be recycled and the production of waste reduced; and biological and land resources such as forests and agricultural soils must be conserved and, where necessary, restored. But while Brown et al. argued that the achievement of sustainable development will require numerous technological and institutional reforms, a fundamental reconsideration of values must also occur:

"In the end, individual values are what drive social change. Progress toward sustainability thus hinges on a collective deepening of our sense of responsibility to the eirth and to future generations. Without a re-evaluation of our personal aspirations and motivations, we will never achieve an environmentally sound global community" (Brown et al., 1990, p. 175). 
This discussion points to several salient characteristics of the literature on sustainable development. Advocates of the sustainability criterion generally mistrust the ability of private market institutions to provide for the welfare of future generations. Accordingly, they emphasize the need for active social intervention to steer the economy towards a sustainable future. These analysts often argue that contemporary environmental and resource problems grow out of prevailing individual and collective values, not just failures of the market mechanism. They are thus willing to use market incentives and policy instruments where appropriate, but well-functioning markets are viewed as a potential tool in the accomplishment of social objectives rather than the goal of policy per se.

In the final analysis, sustainability may be viewed as an ethical framework for the discussion and comparison of alternative development paths: What kind of world do we wish to leave behind to future generations, and what changes in values and social institutions will be required to bring that vision to fruition? Given the inherently.subjective nature of these questions, it is not surprising that it is difficult to fully operationalize the sustainability criterion as a tool in applied policy analysis. Nonetheless, the concept offers a powerful and flexible approach to the understanding of contemporary resource and environmental problems that, in conjunction with conventional analytical techniques, may contribute significantly to policy formulation. 


\section{AN INTEGRATED APPROACH TO POLICY}

What are the implications of the normative criteria discussed above when applied to the analysis of climate policy? Policy discussions often concentrate on balancing the "costs" and "benefits" of greenhouse gas emissions abatement. While this would seem to suggest the use of formal cost-benefit techniques as the favored means of policy analysis, we believe that such a focus is on the whole inappropriate. Cost-benefit techniques are useful in translating the potential impacts of climate change and mitigation schemes into common monetary units when those impacts are physically well-defined and measured. As we have seen, however, evaluating the economic impacts of climate change is no easy task; the most worrisome potential impacts are not definable even in physical terms, and we lack the shadow prices necessary to attach monetary values to impacts such as storm intensification and mass species extinction with any degree of confidence.

This does not mean that provisional cost-benefit evaluations are unable to provide important insights. If, for example, we found that the quantifiable benefits of greenhouse gas abatement measures exceeded their cost, then such measures would clearly offer opportunities to improve the welfare of all individuals while leaving none worse off, provided that net benefits were distributed so as to compensate potential losers. Both the Nordhaus (1991b) and Cline (1992a, 1992b) analyses are useful in this regard - not because they identify an "optimal" level of emissions abatement, but because they offer a minimum abatement level that is mandated given partial quantification and widely accepted moral commitments. Indeed, this position is anticipated by Cline (1992b, p. 311):

"Some will argue that the issue [of climate policy] cannot be decided [through costbenefit analysis], and in particular that it is the unquantifiable ecological effects that should dominate the analysis rather than the measurable impacts considered here. However, that argument reinforces the result here rather than reversing it, because the analysis concludes that aggressive abatement action is justifiable on economic grounds alone and thus would be all the more warranted if further ecological considerations were added."

A key problem in climate policy formulation is balancing the interests of present and future generations and peoples of different world regions. A perceived benefit of climate stabilization is that it reduces risks to the welfare of future generations, particularly those future persons most vulnerable to climate fluctuations because their poverty renders them susceptible to the vagaries of nature. The United Nations Framework Convention on Climate Change (Article 3, paragraph 1), for example, holds that the nations of the world should act to:

"protect the climate system for the benefit of present and future generations of humankind, on the basis of equity and in accordance with their common but differentiated responsibilities and respective capabilities. Accordingly, [developed countries] should take the lead in combating climate change and the adverse effects thereof."

We need not monetize such perceived benefits to take them seriously in policy analysis and decision-making. Indead, they reflect a sentiment that denies the appropriateness of using 
monetary calculations in mediating claims of justice. "Thou shalt not kill" has seldom been interpreted to mean "kill only when the monetary benefits outweigh the monetary costs."

Some analysts hold that the future impacts of climate change are too uncertain to justify the expenditure of present-day resources to mitigate climate change as such. Such analysts argue for a "no-regrets" policy, whereby greenhouse gas mitigation measures are implemented only if they yield clear benefits in ameliorating other social problems. C. Boyden Gray and David B. Rivkin, Jr. (1991, pp. 49-51) - both high-ranking officials in the Bush Administration argue that:

"[F]idelity to the global warming disaster thesis has become ... a litmus test of true environmentalism. Adherents to this position call for revolutionary changes in human behavior. Specifically, they demand that carbon emissions into the atmosphere ... [be] capped around the year $2000 \ldots$ [T] he debate has acquired distinct ideological overtones, and the more skeptical scholars have been branded as heretics and cranks... It would be irresponsible to commit disproportionate resources to solving a quandary whose very existence and severity are still uncertain, and thereby draw resources away from more concrete problems."

In the extreme, the "no regrets" approach might seem to suggest that no emissions abatement should be undertaken whatsoever. One might argue, for example, that steps to reduce energyrelated emissions of carbon dioxide would impose measurable costs without generating associated benefits. Such an interpretation is not conceptually sound. Chlorofluorocarbons, for example, are scheduled to be phased-out under the Montreal Protocol because of their potential impacts on the stratospheric ozone layer. While this step will hardly solve the problem of climate change, it will significantly reduce the burden of greenhouse gases accumulating in the atmosphere.

How far would a no-regrets strategy go in reducing net emissions of carbon dioxide? We know that tropical deforestation is caused in part by inefficient policies that promote land-use changes through direct and indirect subsidies. The no-regrets framework suggests that deforestation rates should be slowed to provide local benefits to developing countries and to preserve biodiversity for the world as a whole. Similarly, many nations subsidize the use of fossil fuels. Germany, for example, subsidizes the use of domestic coal in the production of electric power; India sells electricity to many users at rates well below marginal cost. Price reform in itself would induce some reductions in greenhouse gas emissions even in the absence of a carbon tax. The evidence also suggests that market imperfections impede the uptake of many cost-effective energy-efficient technologies. A no-regrets policy would include measures to reduce those barriers and accelerate efficiency improvements.

The achievement of substantial long-term reductions in greenhouse gas emissions, however, implies moving beyond no-regrets measures to policies with costs ranging from ambiguous to quite substantial. The costs of maintaining current climatic conditions, while unknown, are painful to consider. Stabilization would require immediate and permanent reductions in carbon dioxide emissions of $60 \%$ or more relative to today's level. Such reductions are arguably politically and socially infeasible. The question is thus not whether we should permit climate change or not, but what steps we should take today to reduce the magnitude and timing of 
change.

One pragmatic approach is to use available information regarding the timing and potential impacts of climate change to place an upper limit on allowable warming. Krause et al. (1989), argue that human and ecological systems could adapt to temperatures some $2.5^{\circ}$ Celsius above the pre-industrial global average provided that the rate of increase was no more than $0.1^{\circ}$ Celsius per decade. Based on this supposition, the authors identify maximum permissible greenhouse gas concentrations for each future date and work backwards to identify emissions constraints. They conclude that global emissions of carbon dioxide in industrialized nations should be reduced by $20 \%$ through 2005 , with reductions of $50 \%$ and $75 \%$ achieved by 2015 and 2030. To support the sustained improvement of living standards, developing countries would be permitted to increase emissions by $50-100 \%$ over the short term, with emissions returning to current levels by 2030 .

This approach is consistent in spirit with the recently approved United Nations Framework Convention on Climate Change (Article 2). This treaty calls for:

"[the] stabilization of greenhouse gas concentrations in the atmosphere at a level that would prevent dangerous anthropogenic interference with the climate system. Such a level should be achieved within a time frame sufficient to allow ecosystems to adapt naturally to climate change, to ensure that food production is not threatened and to enable economic development to proceed in a sustainable manner."

The agreement mandates industrialized nations to return "anthropogenic emissions of carbon dioxide and other greenhouse gases not controlled by the Montreal Protocol" to their 1990 levels by the year 2000 (Article 4, paragraph 2(b)).

What would it cost to implement such a proposal? As we saw in Chapter IV, reducing carbon dioxide emissions in the United States by $20 \%$ by the year 2010 would require the imposition of a carbon tax of perhaps $\$ 100$ per tonne. The net economic impacts of such a tax would depend on its coordination with other government policies. If carbon tax revenues were returned to consumers in the form of lump-sum transfers, the achievement of a $20 \%$ emissions reduction by 2010 would reduce future economic activity by some $1-2 \%$. If, on the other hand, the revenues were used to reduce distortionary taxes on labor and capital investment, the negative impacts would be substantially reduced. Indeed, well-designed policies could even stimulate economic growth. Similar results have been established for other industrialized nations.

One could not credibly advance a carbon tax as a demonstrated zero-cost approach to climate stabilization. The impacts of moderate emissions abatement on subjective human welfare, however, are ambiguous. Suppose we assume that a $20 \%$ reduction in carbon dioxide emissions by the year 2010 would result in a mid-range reduction of $1 \%$ in economic activity in the industrialized world. Phased in gradually over time, this change would reduce economic growth by only $0.05 \% / y r$. With the exception of workers in directly affected sectors such as coal mining and the supply of energy-efficient equipment, these changes would be imperceptible to most members of society. Perceived losses, where they occurred, could presumably be compensated over the course of two decades through job retraining and other programs 
appropriate in a dynamic economy characterized by ongoing structural change.

We have established that greenhouse gas emissions, if left unmitigated, threaten to produce uncertain but potentially serious impacts on the welfare of future generations. Catastrophic change is a distinct possibility, and although their timing and probability cannot be ascertained, catastrophe scenarios are consistent with prevailing knowledge of the interactions between climate and biogeochemical systems. We have good reason to believe that the cost of reducing greenhouse gas emissions in the industrialized nations are today zero or negative at the margin, while moderate abatement would impose modest costs that would have no noticeable impact on the subjective well-being of most individuals. To move from these emergent facts to clear policy recommendations requires use of a corollary of the sustainability principle:

(P1) Inhabitants of today's world are morally obligated to take steps to reduce catastrophic risks to members of future generations if doing so would not noticeably diminish their own quality of life.

This form of argument does not require a precise characterization of the impacts of climate change on future society, nor does it imply that the probabilities of extreme events must be calculated with confidence. Instead, we construct a simple two-part test based on the concept of operational thresholds. Is there a non-trivial risk of catastrophic change? Can we reduce that risk without compromising our own well-being? The greenhouse gas emissions guidelines embodied in the U.N. Climate Convention would seem to pass both parts of this test. A case can therefore be made that the industrialized nations are morally obligated to restore carbon dioxide emissions at current levels by 2000 and reduce them by $20 \%$ by 2010 .

Do emissions reductions of this magnitude exhaust our obligations to provide a stable and benign climate to future generations? There is no purely technical answer to this question; the answer hangs on one's moral commitments and interpretation of the sustainability criterion as applied to climate change. Suppose we strengthen P1 to read:

(P2) Inhabitants of today's world are obligated to "revoke risky activities that jeopardize future needs for the sake of less urgent contemporary interests ... well beyond the minimum requirements of subsistence" (Malnes, 1990, p. 62).

Under this premise, a more aggressive approach to climate stabilization would clearly be warranted. But whether P1 or P2 should be used as the basis for policy analysis and management is not for the analyst to decide.

Over the longer term, the stabilization at global temperatures at a level no higher than $2.5^{\circ} \mathrm{C}$ above the pre-industrial average represents a formidable policy challenge. As Krause et al. (1989) note, this would require the reduction of global carbon dioxide emissions by $75 \%$ through 2050. While this level of emissions abatement may turn out to be feasible in the context of a growing world economy, it will require unprecedented improvements in energy efficiency and the development and implementation of low-carbon technologies that supply energy in convenient forms at low cost.

In taking steps to reduce emissions today, we ease the transition by reducing the level of 
emissions abatement required at future dates. But emissions abatement itself is only one means of providing future generations with flexibility in responding to the threat of climate change. Economic theory instructs us that the private sector has weak incentives to develop new technologies, especially when their payoffs are uncertain and consigned to the distant future (Arrow, 1962). Accordingly, the sustainability principle suggests a role for government in developing the technologies required to achieve climate stabilization.

The sustainability principle sheds light on the appropriate sharing of burdens between North and South. While the primacy of the sustainability rule is sometimes attacked on the grounds that we should take care of today's poor before worrying about the future, principles of intergenerational justice flow logically from principles of justice between contemporaries (Howarth, 1992; see also Dower, 1983; Malnes, 1990) - the distinction between the two is based on a false premise. The structure of P1 and the language of the U.N. Climate Convention imply that the costs of climate stabilization should be borne by those most able to manage them - the wealthy nations of the industrialized North. Indeed, climate stabilization arguably implies the transfer of technology and other assets from North to South to permit sustained development while limiting the growth of greenhouse gas emissions.

Finally, we return to the appropriate role for economics in the analysis of climate stabilization policy. We have already discussed our skepticism regarding the use of cost-benefit analysis in the identification of an "optimal" policy response. Nonetheless, we believe that thoughtful and proficient economic analysis can contribute substantially to policy formulation. On the one hand, economics provides a means of modeling the impacts of stabilization measures on employment, economic growth, and other variables of interest. We cannot identify the appropriate level for a carbon tax, for example, unless we know how the tax will influence greenhouse gas emissions.

The normative tools of economics also have much to offer. Given specified greenhouse gas emissions targets, for example, it makes sense to achieve those targets at least possible cost. Here cost-benefit analysis is on relatively solid ground. For although disputes continue regarding the appropriate mix of pricing and regulatory measures in achieving least-cost emissions reductions, there is ample scope for analyses based on real-world observations supplemented by corresponding advances in theory.

The issue of climate change does not imply a narrow choice between the sustainability principle and cost-benefit analysis in the formulation and evaluation of policy. Instead, it challenges us to adopt a strategy of methodological pluralism (Norgaard, 1985, 1989), weaving together the insights gleaned from complementary scientific, ethical, and economic frameworks to achieve a synthetic view that is greater than the sum of the parts. The Laplacean ideal of integrating all knowledge into one grand systems model is beyond the grasp of human possibility. In its stead, we are left with small and partial models and a limited understanding of the interdependencies between human and natural systems. In this scheme, we must leave room for the qualitative dimensions of social ethics, for although they defy quantification, they are fundamental to dialogue that defines good policy and the progressive society. 


\section{BIBLIOGRAPHY}

Arrow, K.J. 1962. "Economic Welfare and the Allocation of Resources for Inventions." In R. Nelson, ed. The Rate and Direction of Inventive Activity. Princeton: Princeton University Press, pp. 141-159.

Arrow, K.J. 1970. Social Choice and Individual Values. 2nd Edition. New Haven: Yale University Press.

Ayres, R.U. and J. Walter. 1991. "The Greenhouse Effect: Damages, Costs and Abatement." Environmental and Resource Economics 1: 237-270.

Bard, E., M. Arnold, P. Maurice, J. Duprat, J. Moyes, and J.C. Duplessy. 1987. "Retreat velocity of the North Atlantic polar front during the last deglaciation determined by ${ }^{14} \mathrm{C}$ accelerator mass spectrometry." Nature 328: 791-794.

Barry, B. 1983. "Intergenerational Justice in Energy Policy." In D. MacLean and P.G. Brown, eds. Energy and the Future. Totawa, New Jersey: Rowman and Littlefield, pp. 1530.

Bator, F. 1957. "The Simple Analytics of Welfare Maximization." American Economic Review 47: 22-59.

Birchfield, G.E. and W.S. Broecker. 1990. "A salt oscillator in the glacial Atlantic?" Paleoceanography 5: 835-843.

Blanchard, O.J. and S. Fischer. 1989. Lectures on Macroeconomics. Cambridge, Massachusetts: MIT Press.

Broecker, W.S. 1987. "Unpleasant surprises in the greenhouse." Nature 328: 123-126.

Broome, J. 1992. Counting the Cost of Global Warming. Cambridge: White Horse Press.

Brown, L.R., C. Flavin, and S. Postel. 1990. "Picturing a Sustainable Society." In Worldwatch Institute. State of the World 1990: A Worldwatch Institute Report on Progress Toward a Sustainable Society. New York: Norton, pp. 173-190.

Brown, P.G. 1992. "Climate Change and the Planetary Trust." Energy Policy 20: 208222.

Brown Weiss, E. 1989. In Fairness to Future Generations: International Law, Common Patrimony, and Intergenerational Equity. Dobbs Ferry, New York: Transnational Publishers.

Cline, W. 1992a. Global Warming: The Economic Stakes. Washington, D.C.: Institute for International Economics. 
Cline, W. 1992b. The Economics of Global Warming. Washington, D.C.: Institute for International Economics.

Dahlman, C. 1979. "The Problem of Externality." Journal of Law and Economics 22: 141-162.

Daly, H.E. and J.B. Cobb. 1989. For the Common Good; Redirecting the Economy Toward Community, the Environment, and a Sustainable Future. Boston: Beacon Press.

Dansgaard, W., J.W.C. White, and S.J. Johnsen. 1989. "The Abrupt Termination of the Younger Dryas Climate Event." Nature 339: 532-534.

d'Arge, R.C., W.D. Schulze, and D.S. Brookshire. 1982. "Carbon Dioxide and Intergenerational Choice. ". American Economic Review 72: 251-256.

Dasgupta, P.S. and G.M. Heal. 1979. Economic Theory and Exhaustible Resources. Cambridge: Cambridge University Press.

Dower, N. 1983. "Ethics and Environmental Futures." International Journal of Environmental Studies 21: 29-44.

Emanuel, K. 1987. "The Dependence of Hurricane Intensity on Climate." Nature 326: 483-485.

EPA (D. Lashof and D. Tirpak, eds.). 1989a. Policy Options for Stabilizing Global Climate: Draft Report to Congress. Washington, D.C.: U.S. Environmental Protection Agency.

EPA (J. Smith and D. Tirpak, eds.). 1989b. The Potential Effects of Global Climate Change on the United States: Report to Congress. Washington, D.C.: U.S. Environmental Protection Agency.

EPA (D. Lashof and D. Tirpak, eds.). 1990a. Policy Options for Stabilizing Global Climate. Washington D.C.: Hemisphere Publishing Company.

EPA (J. Smith and D. Tirpak, eds.). 1990b. The Potential Effects of Global Climate Change on the United States. Washington, D.C.: Hemisphere Publishing Corporation.

Freeman, A.M., III. 1979. The Benefits of Environmental Improvement: Theory and Practice. Baltimore: Johns Hopkins University Press.

Gleick, P.H. 1992. "Effects of Climate Change on Shared Fresh Water Resources." In I. Mintzer, ed. Confronting Climate Change: Risks, Implications and Responses. Cambridge: Cambridge University Press, pp. 127-140.

Gleick, P.H. and E.P. Maurer. 1990. Assessing the Costs of Adapting to Sea Level Rise. A Case Study of San Francisco Bay. Stockholm: Stockholm Environment Institute. 
Goodland, R. and G. Ledec. 1987. "Neoclassical Economics and Principles of Sustainable Development." Ecological Modeling 38: 19-46.

Gray, C.B. and D.B. Rivkin, Jr. 1991. "A 'No Regrets' Environmental Policy." Foreign Policy N83: 47-64.

Green, R.M. 1981. "Intergenerational Distributive Justice and Environmental Responsibility." In E. Partridge, ed. Responsibilities to Future Generations. Buffalo: Prometheus, pp. 91-101.

Haines, A. 1990. "The Implications for Health." In J. Leggett, ed. 1990. Global Warming: The Greenpeace Report. New York: Oxford University Press, pp. 149-162.

Hameed, S. and R. Cess .. 1983. "Impact of a Global Warming on Biospheric Sources of Methane and Its Climatic Consequences." Tellus 35B: 1-7.

Harrod, R.F. 1948. Towards a Dynamic Economy. London: Macmillan and Company.

Heusser, C.J. and J. Rabassa. 1989. "Cold climatic episode of Younger Dryas age in Tierra del Fuego." Nature 328: 609-611.

Hoffert, M.I. 1992. "Climate Sensitivity, Climate Feedbacks and Policy Implications." In I. Mintzer, ed. Confronting Climate Change: Risks, Implications and Responses.

Cambridge: Cambridge University Press, pp. 33-50.

Holling, C.S. 1982. "Myths of Ecology and Energy." In L.C. Ruedisili and M.W. Firebaugh, eds. Perspectives in Energy. London: Oxford University Press, pp. 8-16.

Houghton, R.A., and G.M. Woodwell. 1989. "Global climatic change." Scientific American 30: 36-44.

Howarth, R.B. 1991a. "Economic Efficiency, Intergenerational Equity, and Uncertainty: The Theory of Climate Policy." Paper presented to the Peder Sather Symposium on Global Climate Change. Berkeley, California, October 16-18.

Howarth, R.B. 1991b. "Intergenerational Competitive Equilibria under Technological Uncertainty and an Exhaustible Resource Constraint." Journal of Environmental Economics and Management 21: 225-243.

Howarth, R.B. 1992. "Intergenerational Justice and the Chain of Obligation." Environmental Values 1: 133-140.

Howarth, R.B. and B. Andersson. 1992. "Market Barriers to Energy Efficiency." Lawrence Berkeley Laboratory, Berkeley, California.

Howarth, R.B. and R.B. Norgaard. 1992. "Environmental Valuation under Sustainable 
Development." American Economic Review 82: 473-477.

Hulm, P. 1989. "A climate of crisis: Global warming and the South Pacific islands." Port Moresby, Papua New Guinea: The Associations of South Pacific Environmental Institutions. Cited in IPCC. 1991b.

IPCC. 1990. Policymakers Summary. Geneva: World Meteorological Organization and United Nations Development Program.

IPCC (Houghton, J.T., ed.). 1991a. Climate Change: The IPCC Scientific Assessment. Cambridge: Cambridge University Press.

IPCC. 1991b. Climate Change: The IPCC Response Strategies. Washington, D.C.: Island Press.

IPCC. 1992. 1992 IPCC Supplement. Geneva: World Meteorological Organization and United Nations Development Program.

Jacobson, J. 1989. "Abandoning Homeland." In State of the World 1989. Washington D.C.: Worldwatch Institute.

Johansson, P.O. 1987. The Economic Theory of Environmental Benefits. Cambridge: Cambridge University Press.

Johnson, R.L. and G.V. Johnson. 1990. Economic Valuation of Natural Resources: Issues, Theory, and Applications. Boulder: Westview Press.

Jorgenson, D.W. and P.J. Wilcoxen. 1991. "Reducing U.S. Carbon Dioxide Emissions: The Cost of Different Goals." In J.R. Moroney, ed. Advances in the Economics of Energy and Resources. Greenwich, Connecticut: JAI Press.

Kalkstein, L.S., R.E. Davis, J.A. Skindlov, and K.M. Valimont. 1986. "The Impact of Human-Induced Climate Warming Upon Human Mortality: A New York Case Study." In Proceedings of the International Conference on Health and Environmental Effects of Ozone Modification in Climate Change. Washington, D.C. Cited in Haines. 1990.

Kane, S., J. Reilly, J. Tobey. 1990. "An empirical study of the economic effects of climate change on U.S. agriculture." Cited in Nordhaus. 1991 .

Kates, R.W. 1979. "Climate and society: lessons from recent events." World Climate Conference, World Meteorological Association, Geneva. Updated in W.J. Maunder, The Uncertainty Business: Risks and Opportunities of Weather and Climate. London and New York: Routledge. Cited in Mitchell and Ericksen. 1992.

Kennett, J.P. 1990. "The Younger Dryas cooling event: an introduction." Paleoceanography 5: 891-895. 
Keyfitz, N. 1992. "The Effect of Changing Climate on Population." In I. Mintzer, ed. Confronting Climate Change: Risks. Implications and Responses. Cambridge: Cambridge University Press, pp. 153-162.

Krause, F., W. Bach, and J. Koomey. 1989. Energy Policy in the Greenhouse, Volume One: From Warming Fate to Warming Limit: Benchmarks for a Global Climate Convention. El Cerrito, CA: International Project for Sustainable Energy Paths.

Krause, F., J. Koomey, and D. Olivier, with H. Becht, D. Bleviss, G. Onufrio, and P. Radanne. 1992. Energy Policy in the Greenhouse: Volume Two. Draft Final Report. El Cerrito, California: International Project for Sustainable Energy Paths.

Lashof, D.A. 1989. "The dynamic greenhouse: Feedback processes that may influence future concentrations of atmospheric trace gases and climatic change." Climatic Change 14: 213-242.

Lave, L. and K. Vickland. 1991. "Adjusting to the Greenhouse Effect: The Demise of Traditional Cultures and the Cost to the USA." Risk Analysis 9: 283-289.

Lele, S. 1991. "Sustainable Development: A Critical Review." World Development 19: 607-621.

Levine, M.D., A. Gadgil, S. Meyers, J. Sathaye, J. Stafurik, and T. Wilbanks. 1991. Energy Efficiency, Developing Nations, and Eastern Europe. Washington, D.C.:

International Institute for Energy Conservation.

Levy, F. and R.J. Murnane. 1992. "U.S. Earnings Levels and Earnings Inequality: A Review of Recent Trends and Proposed Explanations." Journal of Economic Literature 30: 1333-1381.

Lewis, J. 1989. "Sea level rise: Some implications for Tuvalu." Ambio 18: 458-459.

Lorius, C., N.I. Barkov, J. Jouzel, Y.S. Korotkevich, V.M. Kotlyakov, and D. Raynaud. 1988. "Antarctic Ice Core: $\mathrm{CO}_{2}$ and Climatic Change Over the Last Climatic Cycle." EOS 79: 681-684.

MacDonald, G.J. 1990. "Role of methane clathrates in past and future climates." Climatic Change 16: 247-281.

Malnes, R. 1990. The Elivironment and Duties to Future Generations - An Elaboration of Sustainable Development. Lysaker, Norway: Fridtjof Nansen Institute.

Manne, A.S. and R.G. Richels. 1991. "Buying Greenhouse Insurance." Energy Policy 6: 543-552.

Manne, A.S. and R.G. Richels. 1992. "The E.C. Proposal for Combining Carbon and 
Energy Taxes - The Implications for Future $\mathrm{CO}_{2}$ Emissions." Forthcoming in Energy Policy.

Mearns, L.O., R.W. Katz, and S. Schneider. 1984. "Extreme high temperature events: Changes in their probabilities with changes in mean temperatures." Journal of Climatic and Applied Meteorology 23: 1601-1613.

Mitchell, J.K. and N.J. Ericksen. 1992. "Effects of Climate Change on Weather-Related Disasters." In I. Mintzer, ed. Confronting Climate Change: Risks, Implications and Responses. Cambridge: Cambridge University Press, pp. 141-152.

National Research Council. 1983. Changing Climate. Washington, DC: National Academy Press.

Nordhaus, W.D. 1989. "The Economics of the Greenhouse Effect." Paper presented to the MIT Workshop on Energy and Environmental Modeling and Policy Analysis, July 31 August 1.

Nordhaus, W.D. 1990. "Economic Policy in the Face of Global Warming." Department of Economics, Yale University, New Haven, Connecticutt.

Nordhaus, W.D. 1991a. "Economic Approaches to Global Warming." In R. Dornbusch and J. Poterba, eds. Global Warming: Economic Policy Responses. Cambridge: Massachusetts Institute of Technology.

Nordhaus, W.D. 1991b. "To Slow or Not to Slow: The Economics of the Greenhouse Effect." Economic Journal 101: 920-937.

Norgaard, R.B. 1985. "An Evolutionary Critique and a Plea for Pluralism." Journal of Environmental Economics and Management 12: 382-394.

Norgaard, R.B. 1989. "The Case for Methodological Pluralism." Ecological Economics 1: 37-57.

Oeschger, H. and I. Mintzer. 1992. "Lessons from the Ice Cores: Rapid Climate Changes During the Last 160,000 Years." In I. Mintzer, ed. Confronting Climate Change: Risks, Implications and Responses. Cambridge: Cambridge University Press, pp. 55-64.

Page, T. 1977. Conservation and Economic Efficiency. Baltimore: Johns Hopkins University Press.

Page, T. 1983. "Intergenerational Justice as Opportunity." In D. MacLean and P.G. Brown, eds. 1983. Energy and the Future. Totawa, New Jersey: Rowman and Littlefield, pp. 31-37.

Page, T. 1988. "Intergenerational Equity and the Social Rate of Discount." In V.K. Smith, ed. Environmental Resources and Applied Welfare Economics. Washington, D.C.:

Resources for the Future. pp. 71-89. 
Parfit, D. 1983. "Energy Policy and the Further Future: The Identity Problem." In D. MacLean and P.G. Brown, eds. 1983. Energy and the Future. Totawa, New Jersey: Rowman and Littlefield, pp. 38-58.

Parry, M.L. 1990. Climate Change and World Agriculture. London: Earthscan.

Parry, M.L. and P.N. Duinker. 1990. "The Potential Effects of Climatic Change on Agriculture." In The IPCC Impacts Assessment. Geneva Switzerland: World Meteorological Organization and United Nations Environment Program, pp. (2-1)-(2-45).

Parry, M.L. and M.S. Swaminathan. 1992. "Effects of Climate Change on Food Production." In I. Mintzer, ed. 1992. Confronting Climate Change: Risks, Implications and Responses. Cambridge: Cambridge University Press, pp. 113-126.

Pearce, D.W., and R.K. Turner. 1990. Economics of Natural Resources and the Environment. Baltimore: John Hopkins University Press.

Peck, S.C. and T.J. Teisberg. 1992. "Cost Benefit Analysis and Climate Change." Electric Power Research Institute, Palo Alto, California.

Perrings, C. 1991. "Reserved Rationality and the Precautionary Principle: Technological Change, Time and Uncertainty in Environmental Decision Making." In Robert Costanza, ed. Ecological Economics; The Science and Management of Sustainability. New York: Columbia University Press, pp. 153-167.

Pezzey, J. 1989. Economic Analysis of Sustainable Growth and Sustainable Development. Washington, D.C.: World Bank.

Pigou, A.C. 1932. The Economics of Welfare. London: Macmillan and Company. Ramsey, F. 1928. "A Mathematical Theory of Saving." 'Economic Journal 38: 543-59

Rawls, J. 1971. A Theory of Justice. Cambridge, Massachusetts: Harvard University Press.

Repetto, R., W. Magrath, M. Wells, C. Beer, and F. Rossini. 1989. Wasting Assets: Natural Resources in the National Income Accounts. Washington D.C.: World Resources Institute.

Revelle, R. 1983. "Methane Hydrates in Continental Slope Sediments and Increasing Atmospheric Carbon Dioxide." In National Research Council. 1983, pp. 252-261.

Riley, J.G. 1980. "The Just Rate of Depletion of a Natural Resource." Journal of Environmental Economics and Management 7:291-307.

Rind, D., R. Goldberg, J. Hansen, C. Rosenzweig, and R. Ruedy. 1990. "Potential Evapotranspiration and the Likelihood of Future Drought." Journal of Geophysical Research 
95: 9983-10004.

Schelling, T. 1992. "Some Economics of Global Warming." American Economic Review 82: $1-15$.

Schimal, David. 1990. "Biogeochemical feedbacks in the earth system." In J. Leggett, ed. Global Warming: The Greenpeace Report. Oxford, England: Oxford University Press.

Schneider, S. 1989. Global Warming. San Francisco: Sierra Club Books.

Schneider, S. 1991. "Three Reports of the Intergovernmental Panel on Climate Change." Environment 33: 25-30.

Schwartz, T. 1978. "Obligations to Posterity." In R.I. Sikora and B. Barry, eds. Obligations to Future Generations. Philadelphia: Temple University Press, pp. 3-13.

Sen, A.K. 1970. Collective Choice and Social Welfare. San Francisco: Holden-Day.

Shackleton, R., M. Shelby, A. Cristofaro, R. Brinner, J. Yanchar, L. Goulder, D. Jorgenson, P. Wilcoxen, and P. Pauly. 1992. "The Efficiency Value of Carbon Tax Revenues." Washington, D.C.: U.S. Environmental Protection Agency.

Solow, R.M. 1974. "Intergenerational Equity and Exhaustible Resources." In Review of Economic Studies, Symposium Issue, pp. 29-45.

Spash, C.L. and R.C. d'Arge. 1989. "The Greenhouse Effect and Intergenerational Transfers." Energy Policy 17: 88-96.

Svedin, U. and B. Aniansson. 1987. Surprising Futures. Swedish Council for Planning and Coordination of Research.

Tietenberg, T. 1984. Environmental and Natural Resource Economics. Glenview, Illinois: Scott Foresman.

Ti.us, J.G. 1991. "Greenhouse Effect ind Coastal Wetland Policy: How Americans Could Abandon an Area the Size of Massachusetts at Minimum Cost." Environmental Management 15: 39-58.

U.S. National Academy of Science. 1991. Policy Implications of Greenhouse Warming Report of the Mitigation Panel. Washington: National Academy Press.

Warrick, R.A. and A.A. Rahman. 1992. "Future Sea Level Rise: Environmental and Socio-Political Considerations." In I.M. Mintzer, ed. Confronting Climate Change: Risks, Implications and Responses. Cambridge: Cambridge University Press, pp. 97-112.

Wigley, T.M.L. and S.C.B. Raper. 1992. "Implications for climate and seal level of 
revised IPCC emissions scenarios." Nature 357: 1443-1446.

Willig, R. 1976. "Consumer's Surplus without Apology." American Economic Review 66: 589-597.

Wilson, R. 1982. "Risk Measurement of Public Projects." In R. Lind, ed. Discounting for Time and Risk in Energy Policy. Washington: Resources for the Future, pp. 205-249.

Woodwell, G.M. 1990. "The Effects of Global Warming." In J. Leggett, ed. 1990.

Global Warming: The Greenpeace Report. New York: Oxford University Press, pp. 116132.

World Commission on Environment and Development. 1987. Our Common Future. Oxford: Oxford University Press. 

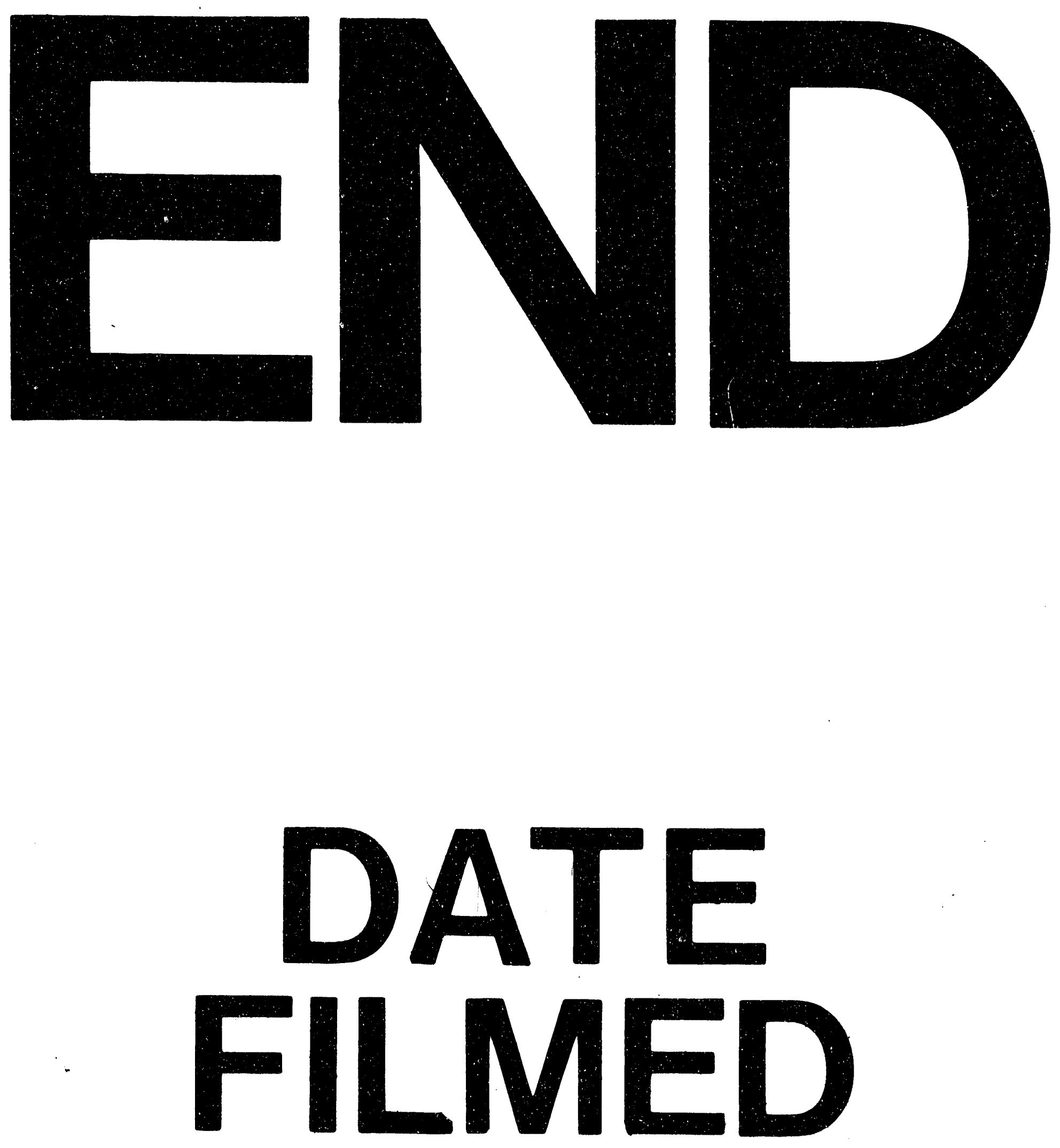

$\frac{\bar{a}}{\overline{3}}$

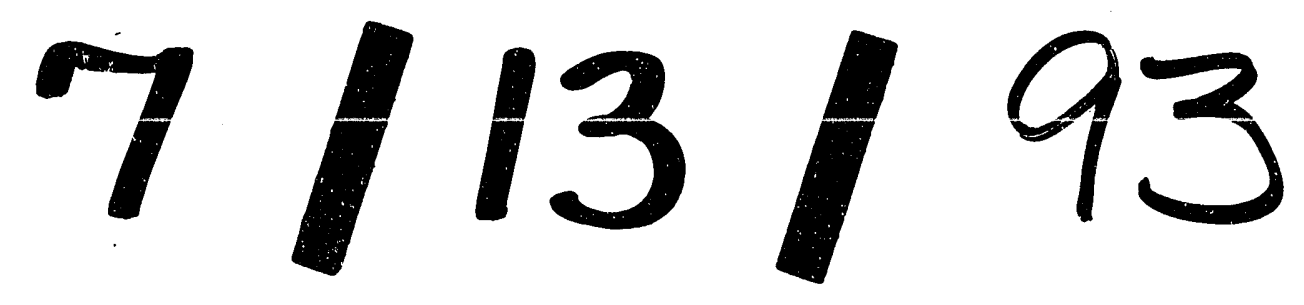


